Article

\title{
Design and Sizing of Mobile Solar Photovoltaic Power Plant to Support Rapid Charging for Electric Vehicles
}

\author{
Kameswara Satya Prakash Oruganti ${ }^{1}\left(\mathbb{0}\right.$, Chockalingam Aravind Vaithilingam ${ }^{1, *} \mathbb{(}$, \\ Gowthamraj Rajendran ${ }^{1}$ (D) and Ramasamy $\mathbf{A}^{2, *}$ \\ 1 School of Engineering, Faculty of Innovation and Technology, Taylor's University Lakeside Campus, \\ No. 1, Jalan Taylor's, Subang Jaya 47500, Selangor, Malaysia; \\ Kameswarasatyaprakashoruganti@sd.taylors.edu.my (K.S.P.O.); \\ gowthamrajrajendran@sd.taylors.edu.my (G.R.) \\ 2 Institute of Power Engineering (IPE), Universiti Tenaga Nasional, Kajang 43000, Selangor, Malaysia \\ * Correspondence: chockalingamaravind.vaithilingam@taylors.edu.my or aravindcv@ieee.org (C.A.V.); \\ agileswari@uniten.edu.my (R.A.); Tel.: +60-12-354-3891 (C.A.V.)
}

Received: 16 July 2019; Accepted: 28 August 2019; Published: 19 September 2019

\begin{abstract}
Existing DC fast-charging stations are experiencing power quality issues such as high harmonics in the line current, poor power factor in the input supply, and overloading of distribution transformers, due to the dynamic behavior of charging patterns when it is connected to the power grid. Most of the recent works involve the usage of renewable energy sources to mitigate the issues on the distribution grid. In order to design a mobile plug and play DC fast charging station, solar energy is the best and viable solution to carry out. In this paper, plug and play solar photovoltaic power plant to charge electric vehicles (EVs) is proposed and modelled using MATLAB/Simulink software. The proposed system can act as a mobile power plant. The controller allows the system to charge the battery, whenever there is abundant solar energy. Incoming EVs will be charged directly from the system battery where the charger acts as a rapid charging system. The proposed system can meet the concept of Solar Photovoltaic Rapid Charging Stations (SPRCS), which shows that $80 \%$ of charge can be fed to an EV in $10.25 \mathrm{~min}$.
\end{abstract}

Keywords: Solar Photovoltaic Rapid Charging Stations (SPRCS); plug and play DER; mobile power plant; PV based charging Station (PVCS); Vehicle to Vehicle power transfer (V2V); Photovoltaic based charging station (PV-EV)

\section{Introduction}

In the present scenarios of carbon emissions from the transportation sector and power, the sector creates alarming situations of a drastic rise in air pollution. Due to the overwhelming response for the Solar Photovoltaic (SPV) and EVs, the context of raise in SPRCS is becoming more favorable. EVs created a paradigm shift for both sectors. Due to the increased growth of the EVs, there are possibilities of global doubling of renewable energy resources. The deployment of Solar Photovoltaic Charging Stations (SPCS) for EVs along with information communication technology (ICT) will maximize the technical features and minimize the operation costs. It is understood that if all the new electric vehicles were going to consume 100\% renewable energy, then around 450 terawatt-hours per year would be required by 2030. Currently, 200,000 public chargers with over $80 \%$ of these are slow chargers [1]. The EVs interact with the grid during charging and discharging modes, which is categorized as V2G and G2V. The primary factor of EVs is that it can act as a potential contributor to grid stability [1]. In Malaysia, there are 192 locally available public charging stations, and 251 chargers [2] 
which consumes $382 \mathrm{MWh}$ extends an estimated electric range of 2,544,350 kilometers and saves $4,85,971$ kilograms of $\mathrm{CO}_{2}$ emissions. The electricity supplied to the chargers is only by conventional methods, therefore it is mandatory that suitable charging stations need to be identified to allow charging infrastructure for charging with slow recharge, accelerated recharge and rapid charging. As of now, most EVs consumers prefer workplace charging and home charging. However, during transit, all the users like to charge their vehicle without any waiting period or delay. Therefore it has given rise to the growth of rapid charging [3,4].

The potential combination of solar energy with rapid charging systems makes the low voltage distribution network free from overloading of distribution transformers, overloading of network feeders and avoids various impacts caused by the charging of EVs. The main requirement for developing the mobile plug and play system is to avoid charging session congestion and to provide flexible charging scenario. Apart from the mentioned need, it is quite difficult to provide onsite solar generation for all the stations. The onsite solar power generation over the System vehicle makes the proposed system act as a distributed energy resources (DER). The system can deploy wherever there is a requirement, i.e., independent of location and it can provide charging and emergency charging session irrespective of the time when there is a request from EVs [5-7]. The need for the mobile EV charging stations is going to be a potential leap towards the charging station development. Due to the mentioned advantages of SPRCS, the proposed model can act as the best solution for a rapid charging station in the near future. The plug and play type SPRCS is presented in Figure 1. The SPRCS can function in two schemes as scheme 1 and scheme 2 . Scheme 1 represents scenario 1 , where the charging request from the incoming EVs is processed. Scheme 2 represents scenario 2, which connects SPRCS to the low voltage distribution grid. The design of rapid charging was considered in this paper.

Scenario 1

Step 1: Measure the SOC of the system Step 2: If SOC is above $40 \%$ connect to EV Step 3: If SOC is below $20 \%$ Disconnect EV

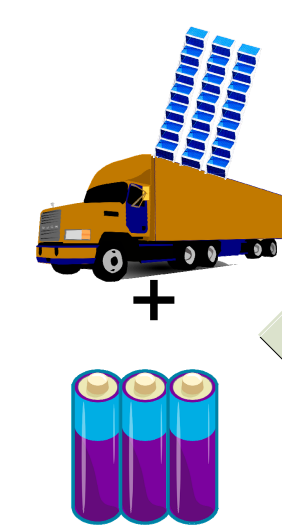

Plug \& Play PV based Service Vehicle

Scenario 2

Step 1: Measure the SOC of the system Step 2: If SOC is above $40 \%$ connect to Grid Step 3: If SOC is below $20 \%$ Disconnect from Grid

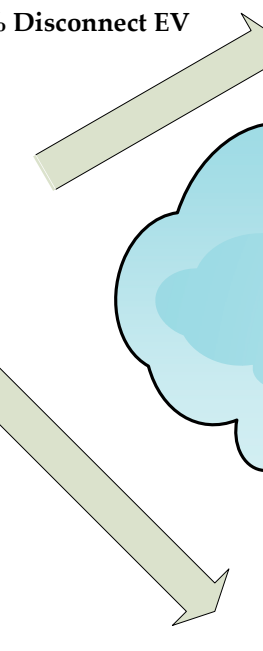

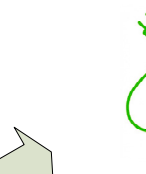
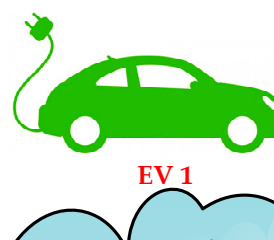

Step 1: Receiving request from EVs

Step 2: Request processing depends on the SOC of the system

Step 3: SPRCS is Dispatched Scenario 2

Step 1: Receiving Request from Distribution System Operator Step 2: Request processing depends on the SOC of the system Step 3: Dispatching service vehicle

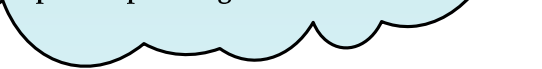

Cloud Based IOT Services

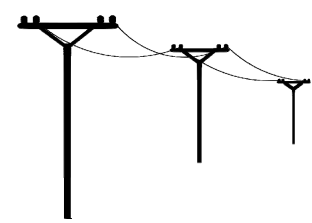

Secondary Distribution Grid

Requesting for Service Vehicle to provide Ancillary Services

Figure 1. Proposed plug and play solar photovoltaic rapid charging station.

\section{Literature Review}

Dai et al. [8] proposes a multi-agent particle Swarm optimization algorithm to improve the utilization of renewable energy resources for charging and discharging pattern of a Battery energy 
storage system (BESS). Kadar et al. [9] investigated different PV-EV charger combinations, and they find that daytime charging in office garages and parking slots are the possible places to charge the cars during work. To perform the load balance between the generation of PV energy and demands caused by the EV, they develop the rule-based charge controller that can schedule the charging service. They come up with various types of PV charger solution like a thin-film PV painted on the car chassis, a home PV system with local storage capacity, and central PV systems at the parking house. Chen et al. [10] developed a real-time power utilizing a strategy for PV based charging with real-time pricing to provide EV with less charging fees. They utilize a particle swarm optimization (PSO) algorithm to allocate the optimized charging power and wavelet-based neural network to forecast pricing for economical charging. They set the system parameters as $60 \mathrm{kWp}$ and $20 \mathrm{EVs}$ of the rated capacity of $100 \mathrm{AH}$. From the developed methodologies, they can show that a $16.5 \%$ reduction in charging cost. Liu et al. [11] analyse optimal charging and scheduling control of EVs with standalone PV charging based on time compensation. They propose an optimal dispatching model to overcome the uncertainties of varying solar generations, and outputs of EVs to maximize the overall economic benefits of standalone PV charging stations. Md Shariful et al. [12] has classified the charging stations as commercial charging, business charging, and home charging. Among the three models, they analyse one model is economically feasible for PV and a battery energy storage system (BESS) to reduce the partial impacts on the grid. In this work, they calculated sizes for PV and BESS for a given number of EVs for commercial charging, business charging, and home charging along with the sensitivity of PV and BESS concerning location. Based on their process, they categorize the test system into weakest, central, and strongest areas according to the strength of PV buses. From their analysis, they confer that PV and BESS based EV charging systems are more suitable at the weakest area of the grid. Demeter et al. [13] come up with a modular technical solution, which can be adapted to any street furniture. Their system consists of $1.6 \mathrm{kWp}$ equipped with an MPPT controller to charge compact electric vehicle such as bicycles, mopeds, and hover, boards. They use Green Test FTV 100 as an SPV efficiency tester to test and measure various parameters. From the parameters, they concluded that provided additional cooling techniques to cool the panel would increase in peak power. A workplace charging station supported by PV is provided in [14]. The authors have propose local production, utilization, and making use of dynamic pricing. They come up with an integrated PV-EV converter for the combined optimization of EV charging with PV generation. They implement mixed linear integer programming (MILP) as recording horizon model predictive control and operated within a fixed time. From the analysis, it is observed that a large portion of $\mathrm{V} 2 \mathrm{G}$ revenue comes from the ancillary services instead of energy sales.

Zhang et al. [15] model a fast-charging station equipped with energy storage. In their work, they come up with intermittent energy storage devices to avoid impacts caused by the uncontrolled charging of EVs. They implement the queuing model to demonstrate the characteristics of loads in a fast-charging station and from the analysis, it confers that intermittent energy storage can allow the charging station to serve more vehicles. Aluisio et al. [16] implement an optimal system with an $11.27 \mathrm{kWp}$ grid connected SPV and five bidirectional EV stations of $10 \mathrm{~kW}$ each. Out of the total value of $19.86 \mathrm{MWh}$, PV covers $76.1 \%$ of production, $16.6 \%$ to EV discharge, and $7.3 \%$ to grid withdrawal. The ratio of grid withdrawal with injection is 0.203 , whereas the ratio of EV discharge to charge is 0.285 . From the analysis, they verified the effectiveness of the EV station commitment strategy is verified. Fadhil et al. [17] simulate solar assisted EVCS with HOMER simulation. The designed system is a $10 \mathrm{kWp}$ solar power plant as a canopy with additional battery storage as a "top-up station" between long-distance public charging stations. From the simulated designs, their system is capable of working even during a power outage. Fathabadi et al. [18] propose a system with hybrid wind and solar of $200 \mathrm{~W}$ with $19.2 \mathrm{kWh}$ lithium-ion batteries and has been constructed to test a prototype which adds $19.6 \mathrm{~km}$ to the cruise range of their plugin hybrid vehicle (PHEV). Eldeeb et al. [19] propose a PV based EV charging station where utilizing of multi-objective optimization to maximise the revenues of the PV-EV station and minimizing the battery energy storage system (BESS) capacity. Esfandyari et al. [20] 
designe a station with $10.5 \mathrm{~kW}$ AC PV array with a $9.6 \mathrm{kWh}$ lithium-ion battery to charge lightweight EVs of $13.76 \mathrm{kWh}$, and monitor it for one year in May, and they find the PV-EV charging station has a higher self-sufficiency of $88 \%$. Islam et al. [21] suggest a combined state of charge (SOC)-based good EV charging strategy to overcome probabilistic or deterministic methods to predict PV productions and charging strategy. This is implemented in the University of Queensland and shows the probability of voltage limit violation is reduced. Bhatti. A [22] demonstrates a rule-based energy management system where using a PV grid-connected system to provide uninterrupted power supply for electric vehicle charging. The above system avoids power system burden by $93.7 \%$ and reduces price by $16.1 \%$ for charging.

Novoa et al. [23] assess control, reliability, and power quality of EVs charging by deploying a PV-based nanogrid. In that, they design four BESS control algorithms, i.e., peak load shifting, minimizing peak period impact, cap demand and PV capture for solar EV charging of the nanogrid. Grande et al. [24] analyse energetic, economic, and environmental viability of a PV-BESS charging station in Madrid, Spain. From that they confirm an off-grid PV-BESS could penetrate $100 \%$ of an EV charging facility and also reduces emissions and pollutants. Karmaker et al. [25] deals with the hybrid solar and biogas for the EV charging station with $10 \mathrm{kWp}$ solar and $6 \mathrm{~kW}$ biogas generators. They claim that the above system could be established anywhere in Bangladesh. Calise et al. [26] propose a novel sustainable mobility scheme where the system consists of a PV panel connected with lead-acid batteries and lithium-ion batteries. It is observed that the sustainable system can avoid the burden of $12 \%$ and $19 \%$ for EVs demand. Badea et al. [27] develop a system where a PV plant generates $5789 \mathrm{kWh} /$ year, and $55.47 \%$ is lost as losses. Klingler [28] conduct a study to show that there will be a rise in stationary batteries with PV for self-consumption in a home-based charging system with an average of $5 \mathrm{~kW}$ PV and 7.5 kWh battery. Marczinkowski et al. [29] analyse customer involvement in establishing residential PV with the battery system and communal system to meet the individual and as well as public electricity demand. Savio [30] design a hybrid microgrid charging station equipped with $12 \mathrm{~kW}$ along with $6 \mathrm{kWh}$ capacity of the battery. Miceli [31] design a university charging station with SPV power utilizing different orientations of east and south. The maximum power required during peak hours is $88 \mathrm{~kW}$ at $08.00 \mathrm{~h}$, and $44 \mathrm{~kW}$ is required between $11.00-13.00 \mathrm{~h}$. Ul-Haq [32] model DC quick EV charging powered by a SPV along with the grid. In their model, the DC voltage remains between $250 \mathrm{~V}$ and $350 \mathrm{~V}$ as a minimum and maximum level, which depends on the SPV production. The simulated results show that three modes of operation are possible in their design of which mode I is when DC voltage is higher than $400 \mathrm{~V}$, mode II when it lies between $250 \mathrm{~V}$ to $350 \mathrm{~V}$ and mode III that is a V2G service.

EVs can also act as a service provider or virtual power plant to feed the ancillary services like frequency regulation, spinning reserve, and supplemental reserve, and replacement reserve services can be met by EVs as V2G services. Bellocchi et al. [33] evaluate the percentage of renewable energy penetration with energy storage. From their analysis, they find that renewable energy resources can penetrate 70\% into the grid. Dominguez-Navarro et al. [34] implement a genetic algorithm (GA) to improve the EV demand model with the utilization of renewable energy resources. Due to the utilization of renewables and storage, the system reduces the impact on the electrical grid. Ma et al. [35] propose a methodology for smooth PV power fluctuations at the point of common coupling and also investigate about smoothing effects, losses, and lifetime of energy storage for hybrid energy storage systems (HESS). They contribute to the development of a control strategy for HESS and PV. Multi-objective optimization is developed to minimize the loss of HESS and SOC by $50 \%$. Pasetti et al. [36] consider a single EV charging service with the photovoltaic system in a public building. The system is equipped with $64 \mathrm{kWp}$ PV system and calculated the Time of Use tariff, in that time of day is the main constraint needed to be considered, and variable tariffs can be used to motivate self-consumption of renewables. Sun et al. [37] analyse a bidirectional wireless power transfer system using a fuzzy adaptive PI controller to charge and discharge the EVs to provide frequency regulations. Han et al. [38] present a PV based combined energy storage station with second-life batteries based on cost estimation. They considered 
a PV combined energy storage system of $354 \mathrm{~kW}$ with charging power capacity of $30 \mathrm{~kW}$ for fast charging and $7.04 \mathrm{~kW}$ of a slow charging station. From their Teaching-Learning-based optimization, they confirm retired electric vehicle batteries could be used in BESS.

As far as the author's knowledge is concerned, there is no work on the standalone solar photovoltaic rapid charging system. There are a few SPV based rapid charging system but these are mostly grid-connected. From the above literature review, the plug and play type SPRCS was proposed to meet the recurring charging demand from EV and as well as to provide ancillary services.

\section{Methodology}

\subsection{PVsyst for Sizing}

For this SPRCS the entire system was modelled and analysed using PVsyst. PVsyst helps to study sizing required for a PV plant, simulating and analysing both on-grid or off-grid systems. It includes extensive loss diagram and identification of system design weakness is possible. For this particular application, like modelling SPRCS for EVs, it was assumed that the load for SPV was constant. As per the sizing of the SPRCS, the load was considered as a lithium-ion battery, and it remained constant for the entire year. Based on this assumption, the load for the SPV was available during $11.00 \mathrm{~h}$ to $15.00 \mathrm{~h}$ based on this charging period and it was observed that $20 \mathrm{kWp}$ SPV could generate approximately 60-66 kWh per day. With this generation, the SPV would be able to generate $120 \mathrm{kWh}$ for two days to charge the system battery of 279 Ah to $90 \%$.

The proposed system consisted of a 3D modular structure based solar photovoltaic (SPV) system ([39] and the supplementary information of ref [39]), MPPT controllers, batteries with an appropriate battery management system (BMS), back-up generator (if needed) and regulators carrying control algorithms to charge the EVs or to provide ancillary services to the local distribution grid. The scheme of the proposed system is shown in Figure 2. The modular system architecture is consisted of any mobile structure which we could utilize to feed the load. For instance, this proposed modular structure consisted of a container, which could hold all the necessary equipment to generate onsite power and could store energy in battery banks. The modular structure consisted of tower-shaped bifacial solar panels. By adopting the tower-shaped structure, the nominal area required to install $20 \mathrm{kWp}$ was reduced predominantly. Therefore 3D solar towers could be placed on the container. Whenever there was a request from the EVs to charge, the request was processed and analysed the data like SOC of the EV, the geographical location of the EV in the de-centralised control room. Based on the requirements, the plug and play vehicle could be dispatched to a particular EV to charge. This particular design for the system was used only for emergency charging for the EVs. The controller would control the battery discharge or incoming demand by the required level of SOC of the incoming vehicle. By doing so, SPRCS could provide enough charge to the incoming vehicle so that it could reach the nearest CS or workplace charging or home charging.

The system could act as a virtual mobile power plant where it could be connected to support the grid wherever the weak bus in the network. The main parameters for the design of service vehicle are in Table 1.

The modular system could be connected to a three phase inverter and then connected to suitable high-speed DC charging equipment like ASEA Brown Boveri (ABB's) Terra 54 CT, [40] as the charging equipment could provide one DC charging session with capabilities of delivering $22 \mathrm{~kW}$ output power. It could even be directly connected to the EVs to facilitate to DC-DC link to provide DC fast charging. The proposed modular System would be capable of completely charging two Nissan leaf of $40 \mathrm{kWh}$ capacity. Therefore the system was designed in such a way that it will charge the EVs required to reach nearest charging location. Further, upon request from the distribution system operator, the SPRCS can be connected to the weaker bus in the distribution network to support ancillary services. 


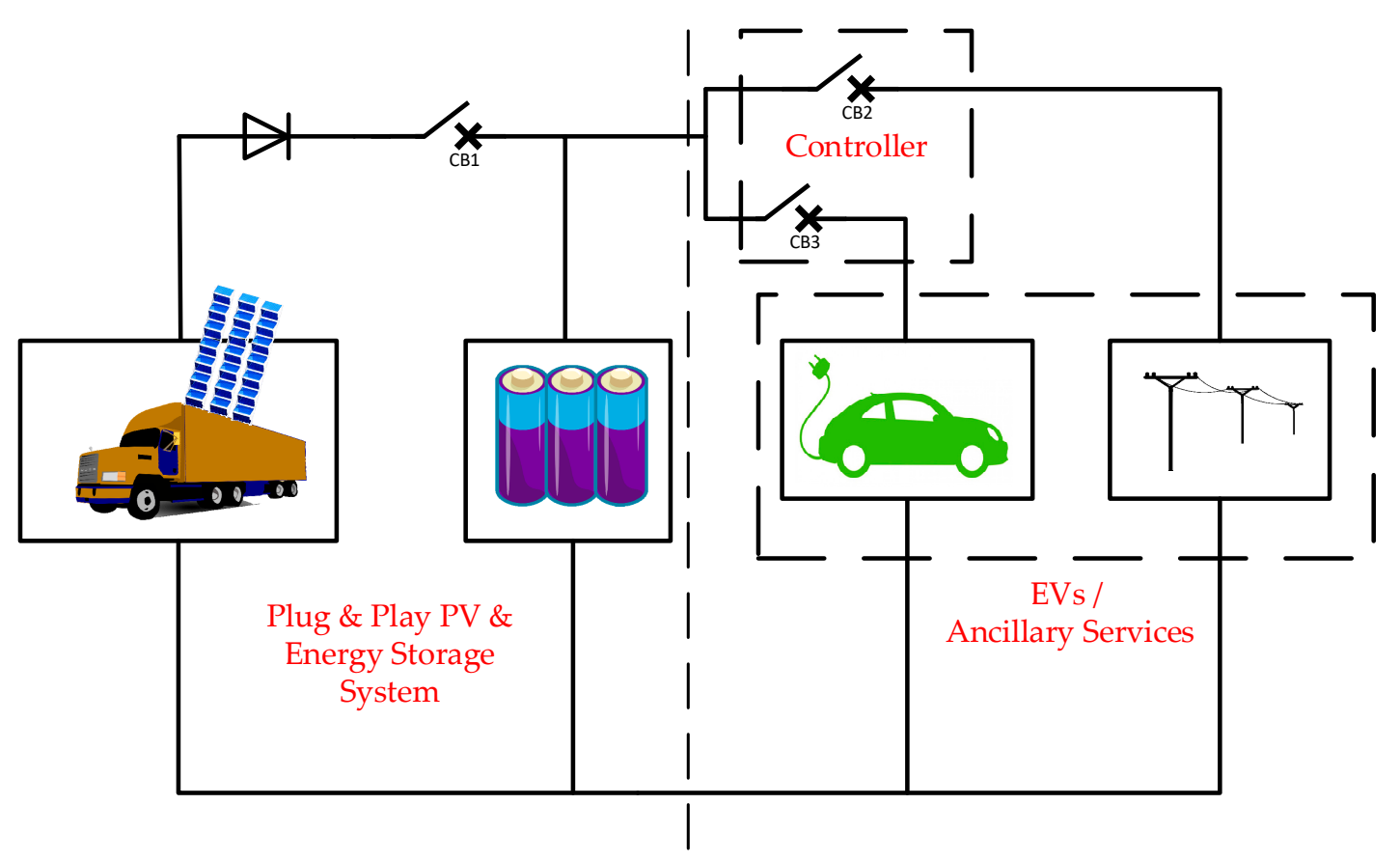

Figure 2. Scheme of the proposed system.

Table 1. Main parameters for the service vehicle.

\begin{tabular}{cc}
\hline Parameters & Value \\
\hline PV Peak power & $20 \mathrm{kWp}$ \\
Approximate units generated & $60-66 \mathrm{kWh}$ \\
Battery capacity & $279 \mathrm{Ah}$ \\
Time need to charge the full battery & 2 days \\
Proposed DC charger & Direct coupler \\
\hline
\end{tabular}

\subsection{Modelling of the Proposed System}

\subsubsection{PV Array Output}

The modelling of the solar photovoltaic system was carried out by considering the work presented in the article [25] PV array output can be determined from the Equation (1).

$$
P_{p v}=S I \cdot \eta \cdot \mathrm{A}
$$

where SI is the annual solar insolation in $\mathrm{kWh} / \mathrm{m}^{2}$, $\eta$ is the efficiency of the solar panel module and A is the surface area of the solar array. The effect of temperature can be considered by the Equation (2) where $\eta t$ is the temperature de-rating effect. As we know, solar panels need to function in the appropriate temperature and if the temperature increases, efficiency decreases, which in turn reduces the power output.

$$
\eta t=1-[\beta \cdot(T C-T S)]
$$

The SPV output depends on the temperature and de-rating effect. The governing equation for SPV output is changed to Equation (3). Where $W$, is the rated capacity of PV panel in $\mathrm{kW}, \beta$ is the temperature coefficient, $G_{C}$ is the solar insolation in real-time condition, $G_{S}$ is the solar insolation in standard test conditions, $T_{\mathcal{C}}$ and $T_{\mathcal{S}}$ are the temperatures of the PV cell at real-time and standard test conditions.

$$
P_{P V}=W \cdot \eta_{t} \cdot\left(\frac{G_{C}}{G_{S}}\right)\left[1+\beta\left(T_{C}-T_{S}\right)\right]
$$


The modular system was designed for the geographical location of Subang Jaya in the peninsular of Malaysia. Due to the varying climatic condition of this place, there are considerably three and a half to four hours of clear sunshine is available. As the proposed model was a 3D modular structure, the PVsyst tool was not able to simulate the proposed structure. So as per the compatibility of the tool, a normal flat roof structure was considered for simulation. In order to get maximum irradiation on the collector plane, the proposed design consisting of fixed tilt was considered despite seasonal tilt. The tilt angle was $3^{\circ}$ Based on the latitude of this location and the yearly irradiation yield on the collector plane was maximum, which was $1600 \mathrm{kWh} / \mathrm{m}^{2}$. The daily irradiance profile for inclined plane at $3^{\circ}$ is shown in Figure 3 followed by the Daily average temperature in Figure 4.

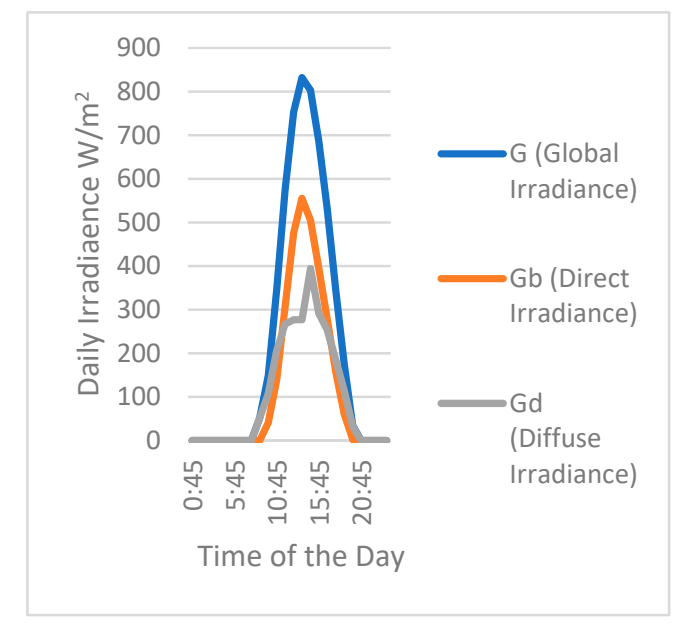

Figure 3. Daily average irradiance.

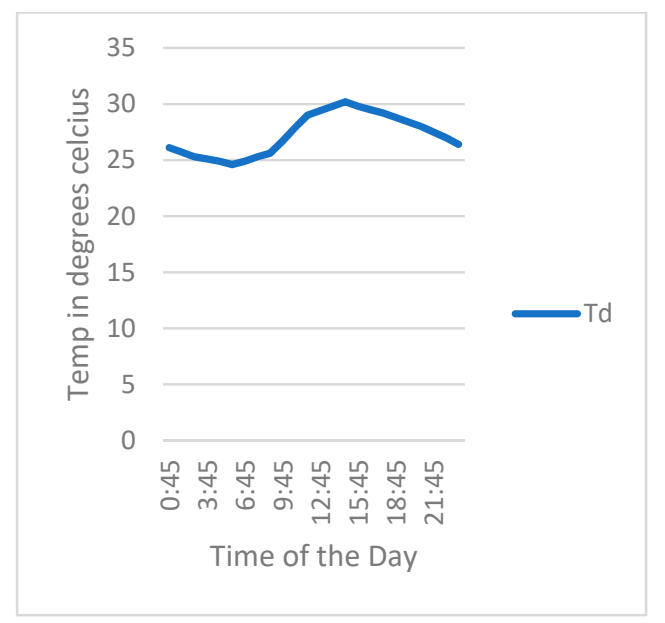

Figure 4. Daily average temperature.

Overall, the system production for the entire year month wise is in Table 2, and overall PV conversion losses were given in Table 3 PV loss due to irradiation level, PV loss due to temperature, module array mismatch, Ohmic wiring loss, and unused energy loss were considered for PV converting efficiency. It showed that in March, there was a massive production of horizontal global irradiation (HGI) of $150.3 \mathrm{kWh} / \mathrm{m}^{2}$. Besides, the global effective corrected incidence angle modifier (IAM) was $145.9 \mathrm{kWh} / \mathrm{m}^{2}$. Available solar energy was $2265 \mathrm{kWh}$ for March. The energy generated from the SPV was enough to charge the system batteries. The energy supplied to the user such as the system batteries consumed $1844 \mathrm{kWh}$ of energy for the entire month of March. The probability of loss-of-load (PLOL) was assumed to be $10 \%$, i.e., the solar fraction was $90 \%$, as given in Figure 5. PVsyst provided pre-sizing requirements in which PLOL was checked over 40 different years and provided an approximate sizing of $20 \mathrm{kWp}$ SPV. 
Table 2. Energy balance of the system.

\begin{tabular}{|c|c|c|c|c|c|c|c|c|}
\hline & $\begin{array}{l}\text { Horizontal } \\
\text { Global } \\
\text { Irradiation }\end{array}$ & $\begin{array}{l}\text { Global Effective } \\
\text { Corrected for IAM } \\
\text { and Shadings }\end{array}$ & $\begin{array}{c}\text { Available } \\
\text { Solar Energy }\end{array}$ & $\begin{array}{c}\text { The Energy } \\
\text { Supplied to } \\
\text { the User }\end{array}$ & $\begin{array}{c}\text { Ambient } \\
\text { Temperature }\end{array}$ & $\begin{array}{c}\text { Effective Energy at } \\
\text { the Output of the } \\
\text { Array }\end{array}$ & $\begin{array}{l}\text { Probability of } \\
\text { "Loss-of-Load" }\end{array}$ & $\begin{array}{c}\text { Duration of } \\
\text { “Loss-of-Load" } \\
\text { (User Not Supplied) }\end{array}$ \\
\hline Month & $\mathrm{kWh} / \mathrm{m}^{2}$ & $\mathrm{kWh} / \mathrm{m}^{2}$ & kWh & kWh & ${ }^{\circ} \mathrm{C}$ & kWh & $\%$ & Hour \\
\hline Jan & 129.4 & 126.7 & 1976 & 1822 & 27.25 & 1990 & 2.85 & 21 \\
\hline $\mathrm{Feb}$ & 131.3 & 128.6 & 2006 & 1595 & 27.73 & 1784 & 6.47 & 44 \\
\hline Mar & 150.3 & 145.9 & 2265 & 1844 & 28.07 & 2085 & 2.58 & 19 \\
\hline Apr & 140.2 & 134.6 & 2104 & 1756 & 27.57 & 1926 & 2.75 & 20 \\
\hline May & 142.5 & 135.6 & 2108 & 1811 & 28.58 & 2045 & 2.90 & 22 \\
\hline Jun & 131 & 124.3 & 1937 & 1755 & 27.81 & 1979 & 5.40 & 39 \\
\hline Jul & 133.3 & 127.1 & 1983 & 1665 & 27.83 & 1857 & 16.64 & 124 \\
\hline Aug & 133.8 & 128 & 1997 & 1766 & 27.79 & 1963 & 8.33 & 62 \\
\hline Sep & 131.2 & 126.6 & 1975 & 1735 & 27.2 & 1926 & 8.13 & 59 \\
\hline Oct & 135.5 & 131.9 & 2054 & 1861 & 27.48 & 2014 & 0.00 & 0 \\
\hline Nov & 119.9 & 117.4 & 1838 & 1664 & 26.69 & 1926 & 11.35 & 82 \\
\hline Dec & 118.9 & 116.6 & 1825 & 1669 & 27.17 & 1799 & 15.19 & 113 \\
\hline
\end{tabular}

Table 3. Losses during photovoltaic (PV) energy conversion.

\begin{tabular}{|c|c|c|c|c|c|}
\hline & $\begin{array}{l}\text { PV Loss due to } \\
\text { Irradiance Level }\end{array}$ & $\begin{array}{l}\text { PV Loss due to } \\
\text { Temperature }\end{array}$ & $\begin{array}{l}\text { Module Array } \\
\text { Mismatch Loss }\end{array}$ & Ohmic Wiring Loss & $\begin{array}{l}\text { Unused Energy Loss } \\
\text { (Full Battery) }\end{array}$ \\
\hline Month & kWh & kWh & kWh & kWh & kWh \\
\hline January & 36.88 & 169.7 & 21.92 & 40.34 & 129.9 \\
\hline February & 30.99 & 192.5 & 22.09 & 43.49 & 357.7 \\
\hline March & 34.1 & 224.6 & 25 & 49.61 & 333.2 \\
\hline April & 34.81 & 191 & 23.2 & 44.23 & 329.3 \\
\hline May & 37.43 & 196.4 & 23.33 & 43.59 & 217.6 \\
\hline June & 37.05 & 165.8 & 21.49 & 38.95 & 107 \\
\hline July & 37.38 & 177.9 & 21.88 & 40.94 & 265 \\
\hline August & 37.71 & 172.4 & 22.11 & 40.52 & 187.4 \\
\hline September & 35.65 & 174.5 & 21.85 & 41.16 & 176.7 \\
\hline October & 35.94 & 184.6 & 22.74 & 43.06 & 178.4 \\
\hline November & 35.69 & 143.7 & 20.41 & 36.46 & 62.4 \\
\hline December & 37.35 & 149.9 & 20.2 & 36.28 & 158.7 \\
\hline
\end{tabular}




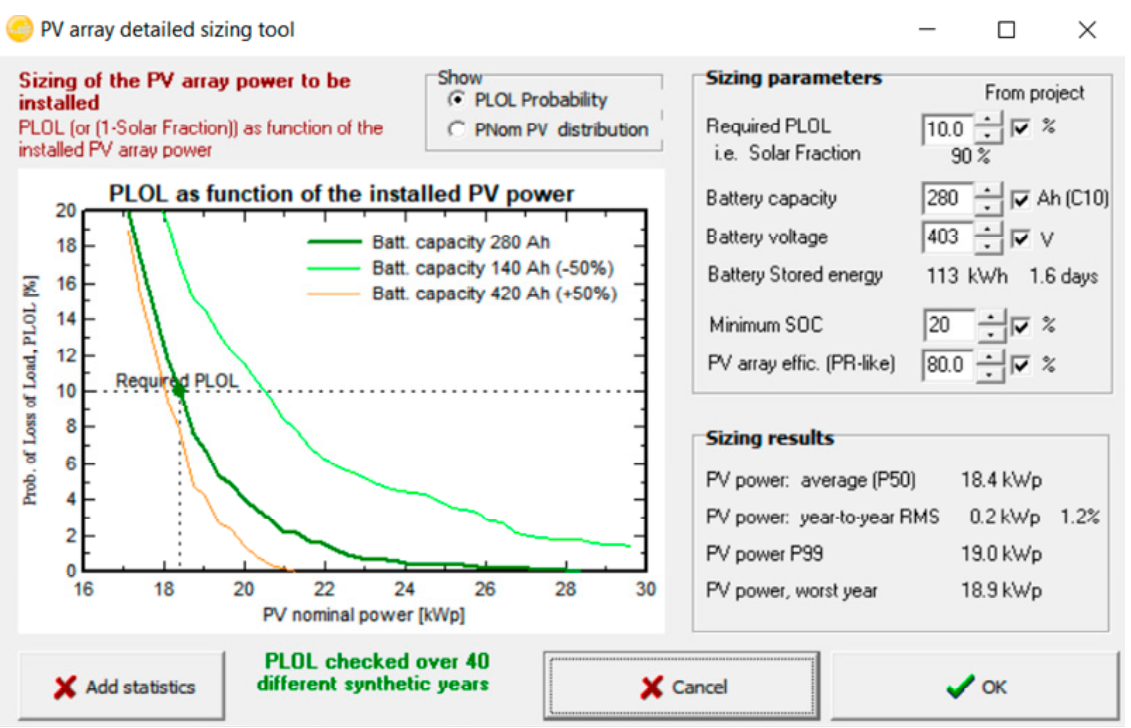

Figure 5. Probability of loss-of-load (PLOL) sizing tool.

Sizing of the SPV required to charge the system batteries is shown in Figure 6. It consisted of pre-sizing suggestions and user needs. The system requirement was to charge the system batteries during a time when abundant solar energy was available. For this work, the sizing of the SPV system was $20 \mathrm{kWp}$. The voltage vs. current (VI) and power vs. voltage (PV) characteristics curve for the PV module CS3U-360P P4 are shown in respective Figures 7 and 8. On average irradiation between $500 \mathrm{~W} / \mathrm{m}^{2}$ to $800 \mathrm{~W} / \mathrm{m}^{2}$, the chosen solar panel was able to produce 198 to $266 \mathrm{~W} /$ module.

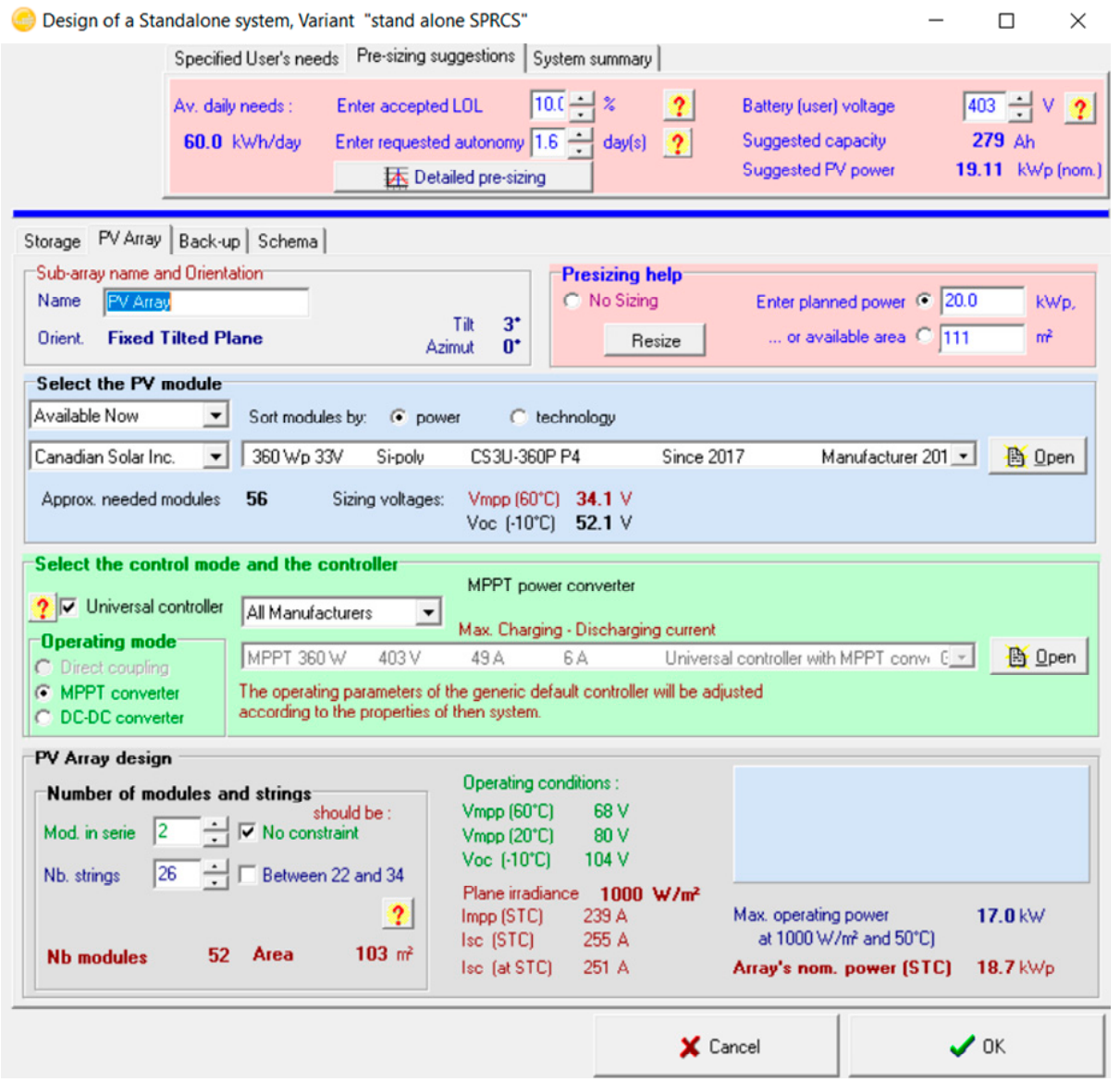

Figure 6. Sizing of standalone PV system for solar photovoltaic rapid charging system (SPRCS). 
PV module: Canadian Solar Inc., CS3U-360P P4

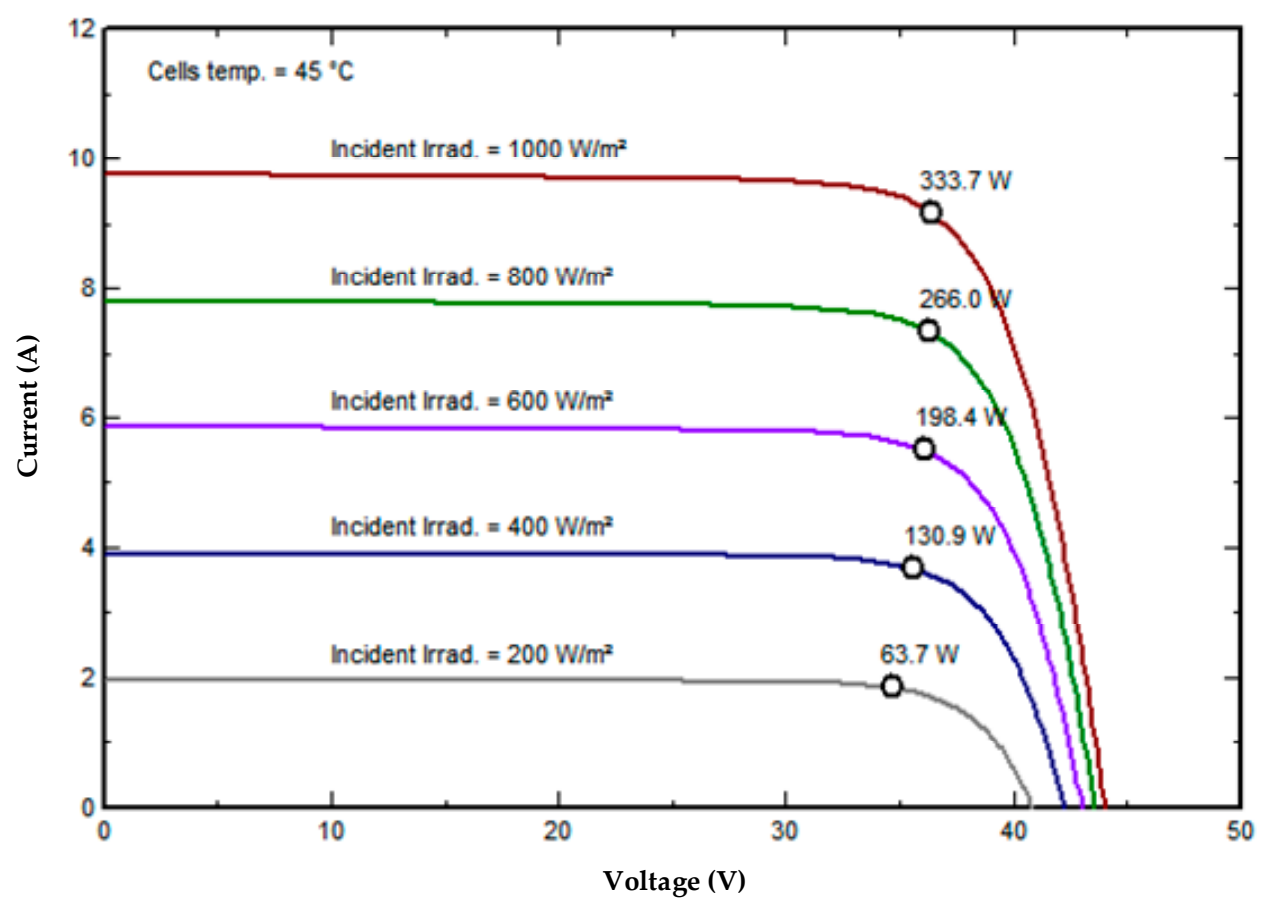

Figure 7. VI characteristics curve for Canadian solar panel CS3U-360P P4.

PV module: Canadian Solar Inc., CS3U-360P P4

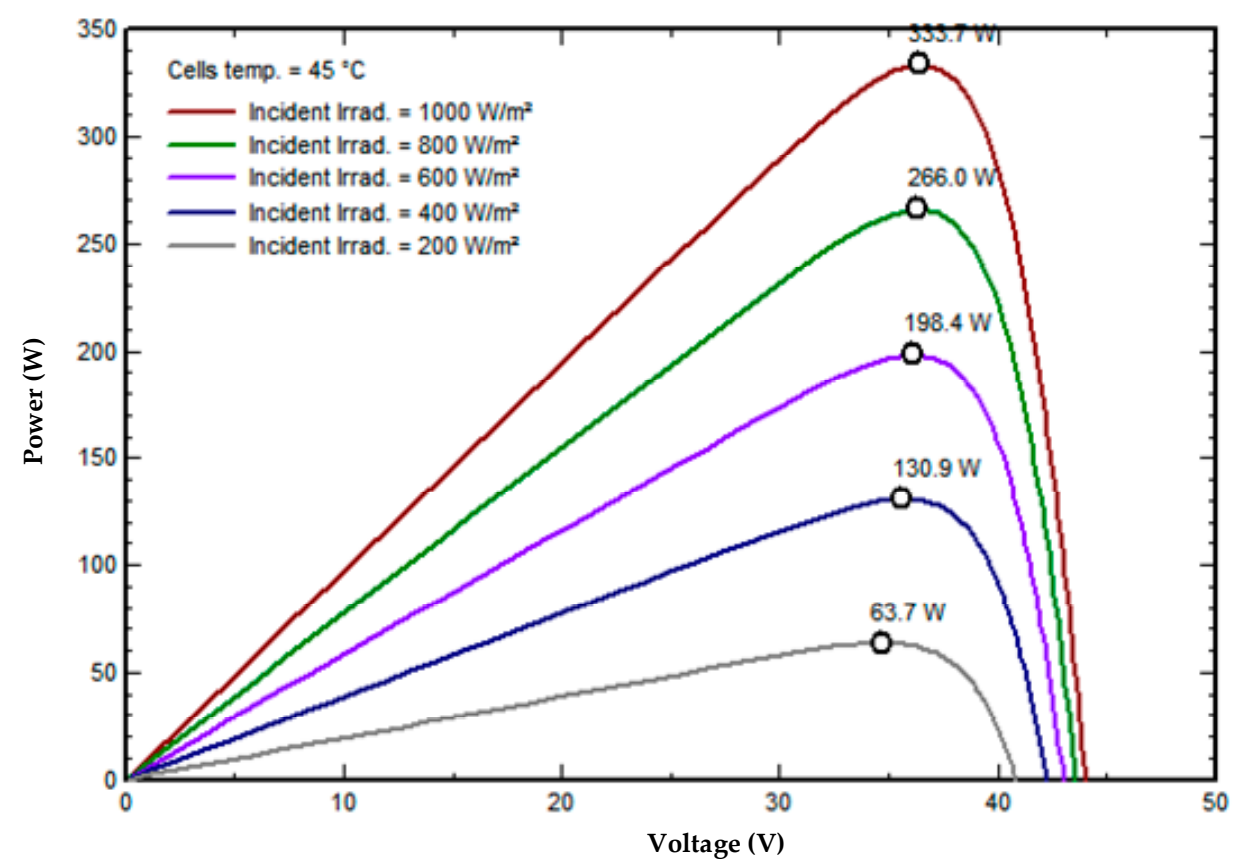

Figure 8. PV characteristics curve for Canadian solar panel CS3U-360P P4.

\subsubsection{Battery Modelling}

Modelling of the battery system was carried out by considering the work presented in the [25] In our system, a lithium-ion battery was used for storing the energy generated from the SPV. The battery capacity is $279 \mathrm{Ah}$. The system battery could be fully charged by utilising solar generation generated for two days. This battery system was going to act as an intermittent storage unit to facilitate rapid charging to EVs. In this system, the intermittent battery storage was designed to have SOC of $90 \%$. 
The charge in the battery can represent by the Equation (4), and initial battery SOC can be represented by Equation (5). The SOC is considered as a random variable with respective to the distance. So the $\mathrm{SOC}$ with respect to distance travelled is represented by Equation (6) where $V_{b a t}, I_{b a t}$ is correspond to the voltage and current needed to charge with respect to time, $d$ and $d_{\text {max }}$ are the distance travelled and maximum distance that can be travelled by an EV.

$$
\begin{gathered}
Q_{\text {Battery }}=S O C+\int_{0}^{t} V_{b a t} I_{b a t} \mathrm{dt} \\
B_{S O C}=\frac{Q_{b a t}}{Q_{b a t, \max }} \\
E=1-\frac{d}{d_{\max }} ; 0<d<d_{\max }
\end{gathered}
$$

Overall, battery performance is presented in Table 4 in which for the entire year, the battery charging/discharging efficiency was maintained at above $90 \%$. During the entire time, the system battery SOC range maintained between $20 \%$ to $90 \%$. It was clear from the simulation that battery-discharging current on average for a day was $47.36 \mathrm{~A}$. With the system voltage of $403 \mathrm{~V}$ the SPRCS was always able to produce approximately more than $17 \mathrm{~kW}$ to the electric vehicles at any time.

Table 4. System Battery Performance.

\begin{tabular}{ccccccc}
\hline & $\begin{array}{c}\text { Average } \\
\text { Battery } \\
\text { Voltage }\end{array}$ & $\begin{array}{c}\text { SOC at the } \\
\text { End of Time } \\
\text { Interval }\end{array}$ & $\begin{array}{c}\text { Battery Current/ } \\
\text { Discharge } \\
\text { Efficiency }\end{array}$ & $\begin{array}{c}\text { Battery Energy } \\
\text { Charge/Discharge } \\
\text { Efficiency }\end{array}$ & $\begin{array}{c}\text { The Current } \\
\text { Required to } \\
\text { Charge Battery }\end{array}$ & $\begin{array}{c}\text { Battery } \\
\text { Discharging } \\
\text { Current }\end{array}$ \\
\hline Month & $\mathbf{V}$ & $\%$ & $\%$ & $\%$ & Ah & Ah \\
\hline January & 419.7 & 31.3 & 96.1 & 95.5 & 1460.4 & 1421.8 \\
February & 428.5 & 35.1 & 91 & 89.5 & 1420 & 1293.2 \\
March & 426.4 & 60.4 & 91.4 & 85.9 & 1559.7 & 1361.8 \\
April & 431.4 & 37.6 & 90.7 & 94.4 & 1413.7 & 1362.1 \\
May & 423.1 & 57.9 & 91.3 & 86.9 & 1605.2 & 1417.6 \\
June & 429.2 & 78.7 & 91.1 & 86 & 1416.3 & 1240.6 \\
July & 422.3 & 77.1 & 90.8 & 90.4 & 1534.1 & 1411.4 \\
August & 419.9 & 76.1 & 91.5 & 90.9 & 1528.8 & 1414.8 \\
September & 424.8 & 70.4 & 90.9 & 91.3 & 1505.9 & 1398.8 \\
October & 426.2 & 25.4 & 90.5 & 98.1 & 1501.3 & 1503.4 \\
November & 414.4 & 78.0 & 91.6 & 80.8 & 1573 & 1294.2 \\
December & 421.5 & 32.8 & 90.6 & 99.2 & 1386.3 & 1401.4 \\
\hline
\end{tabular}

The charge/discharge vs. state of charge (SOC) and discharge characteristics curve for C10 are shown in Figure 9a,b. In that, the curve shows that the battery is capable of charging at $56 \mathrm{~A}$ for $5 \mathrm{~h}$, $14 \mathrm{~A}$ for $20 \mathrm{~h}$. Similarly, the battery could discharge at $55.8 \mathrm{~A}$ for $5 \mathrm{~h}$. The discharge profile of the system was designed for C10. System batteries would discharge at $403 \mathrm{~V}$ at a nominal capacity of C10. From the curve, it was visible that for charging, cut-off voltage was $58.8 \mathrm{~V}$ and discharging, cut-off voltage was 35.0 V. Battery modelling was carried out in PVsyst, as shown in Figure 10. The chosen batteries were $50.4 \mathrm{~V} 279$ Ah lithium-ion. 


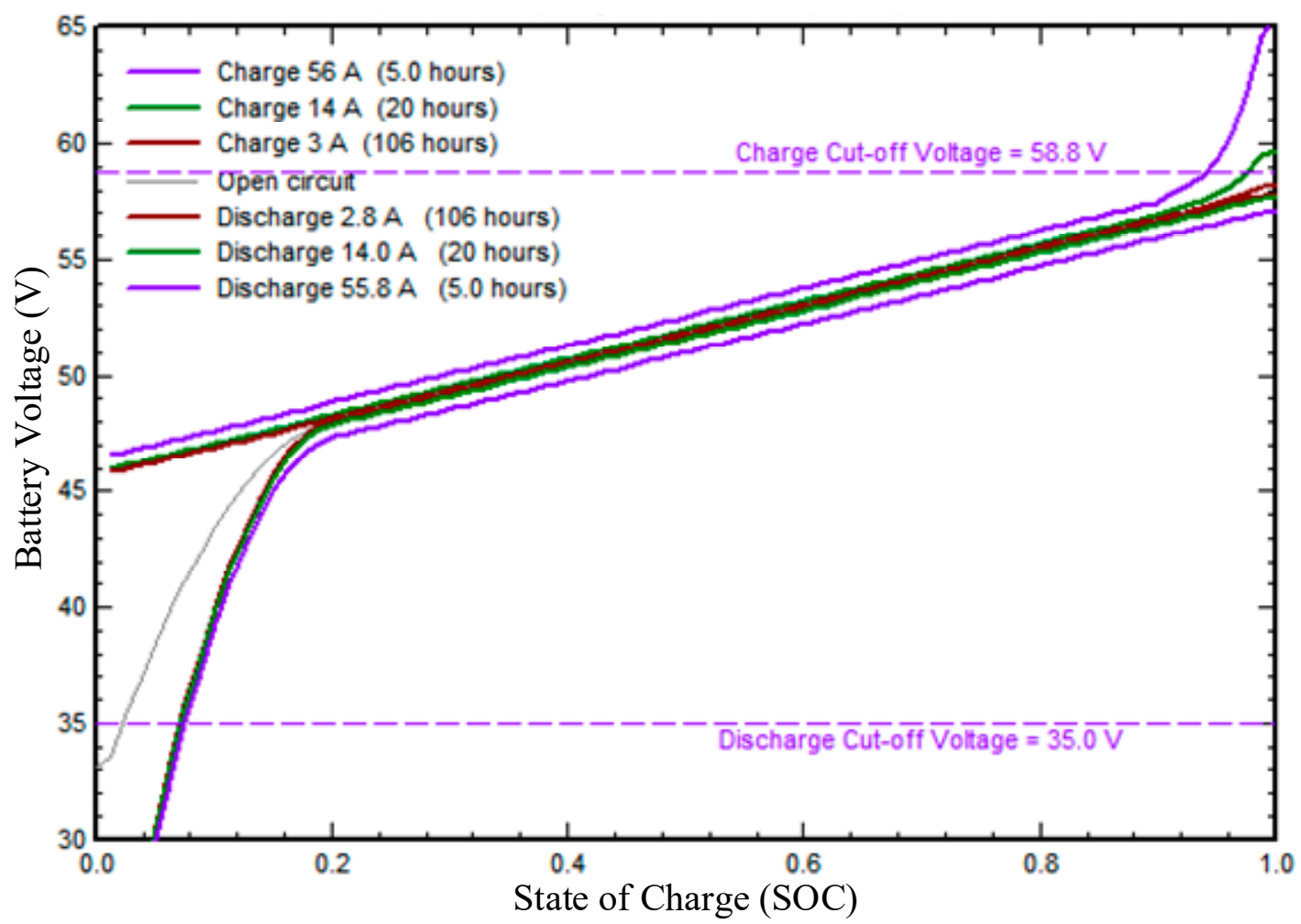

(a)

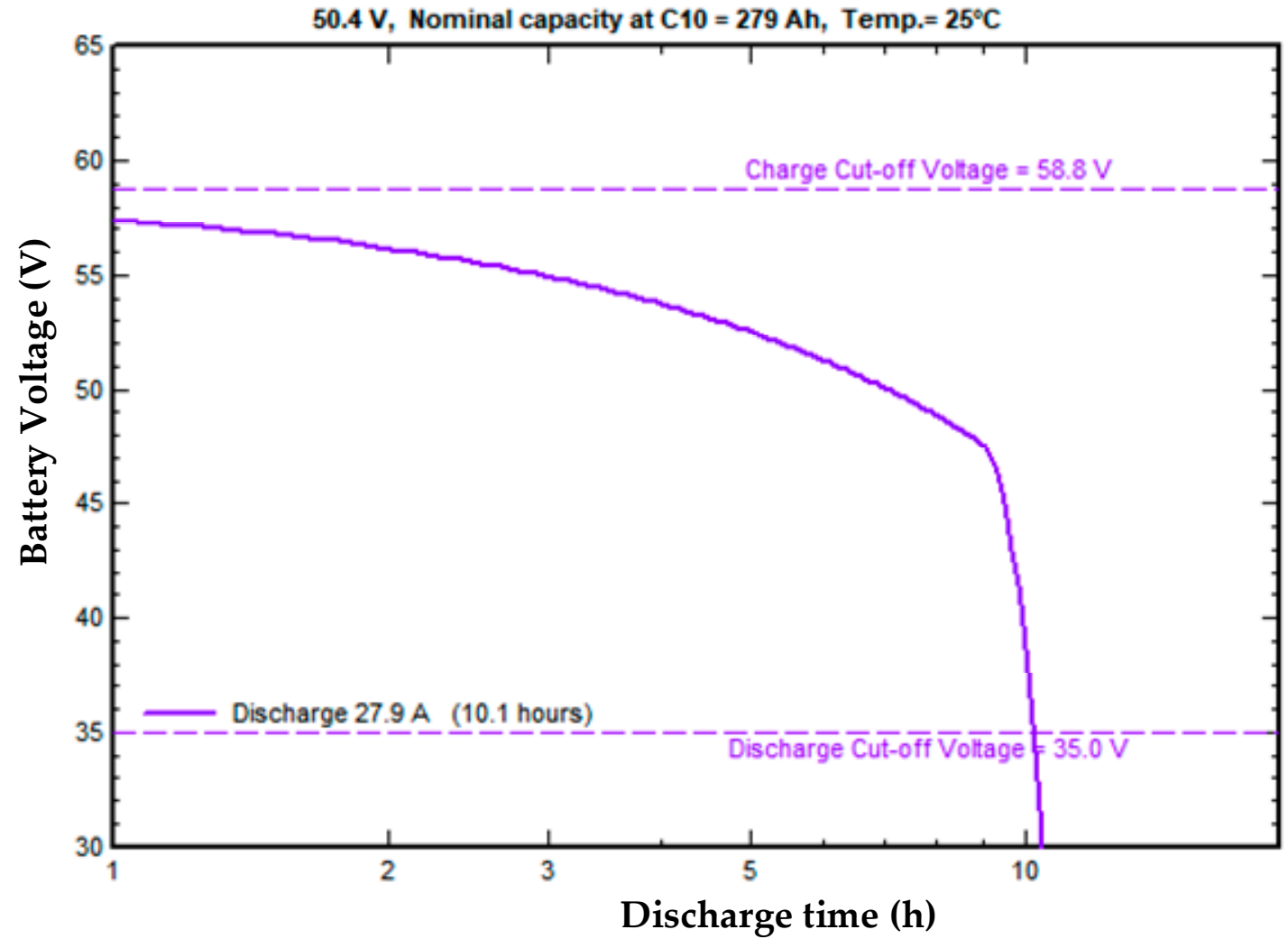

(b)

Figure 9. (a) Characteristics curve between charge/discharge vs. state of charge (SOC); (b) discharge characteristics curve. 
Design of a Standalone system, Variant "stand alone SPRCS" Specified User's needs Pre-sizing suggestions | System summary |

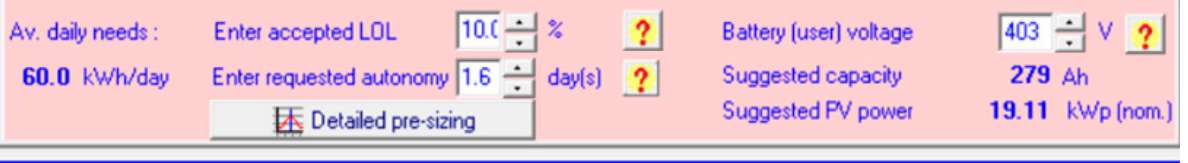

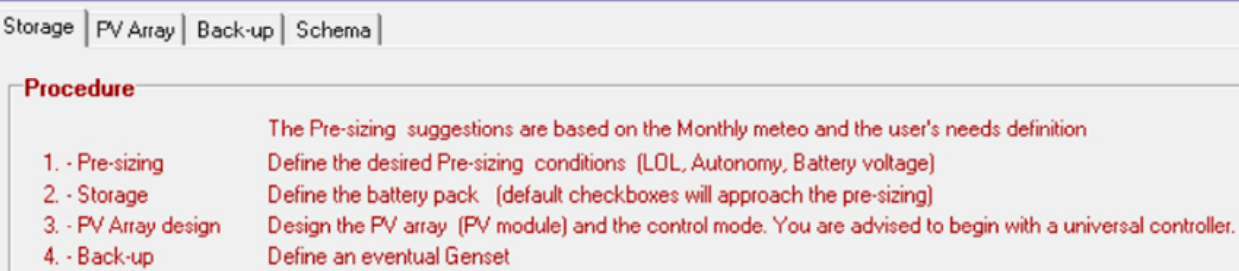

\section{Cancel}

Figure 10. Designing of on-board storage system for SPRCS.

\subsubsection{Electric Vehicle Demand}

Power consumed by EV is with respect to the distance travelled, battery capacity and mode of driving [25]. Therefore, the general power requirement can be analysed by the following equations:

$$
\begin{gathered}
P_{D}=\frac{K_{d} \cdot E_{k}}{T} \\
P_{D}=\frac{Q_{b a t} \times\left(S O C_{\max }-S O C\right)}{T} \\
P=\sum_{i=1}^{N} P_{D}
\end{gathered}
$$

From Equation (7), $K_{d}$ is kilometer driven, $E_{k}$ is energy required per kilometer, and $T$ is the time required to charge the vehicle. The above equation held good in our system as the central battery storage unit needed to charge from the SPV. The power demand could be represented by Equation (8) where $Q_{b a t}$ is battery capacity, $S O C_{\max }$ is the upper limit of battery $S O C$, and $T$ is the time required to reach $S O C_{\max }$. Total power required for $\mathrm{N}$ number of vehicles can be calculated from Equation (9). 


\subsection{Proposed Algorithm}

In order to control the system battery to charge a limited amount of energy in the EV, a robust algorithm is needed where it can be variable depending on the sequences and dynamic constraints. The following algorithm is shown in Figure 11 and it acts as a basis for simple control for discharging of the system battery.

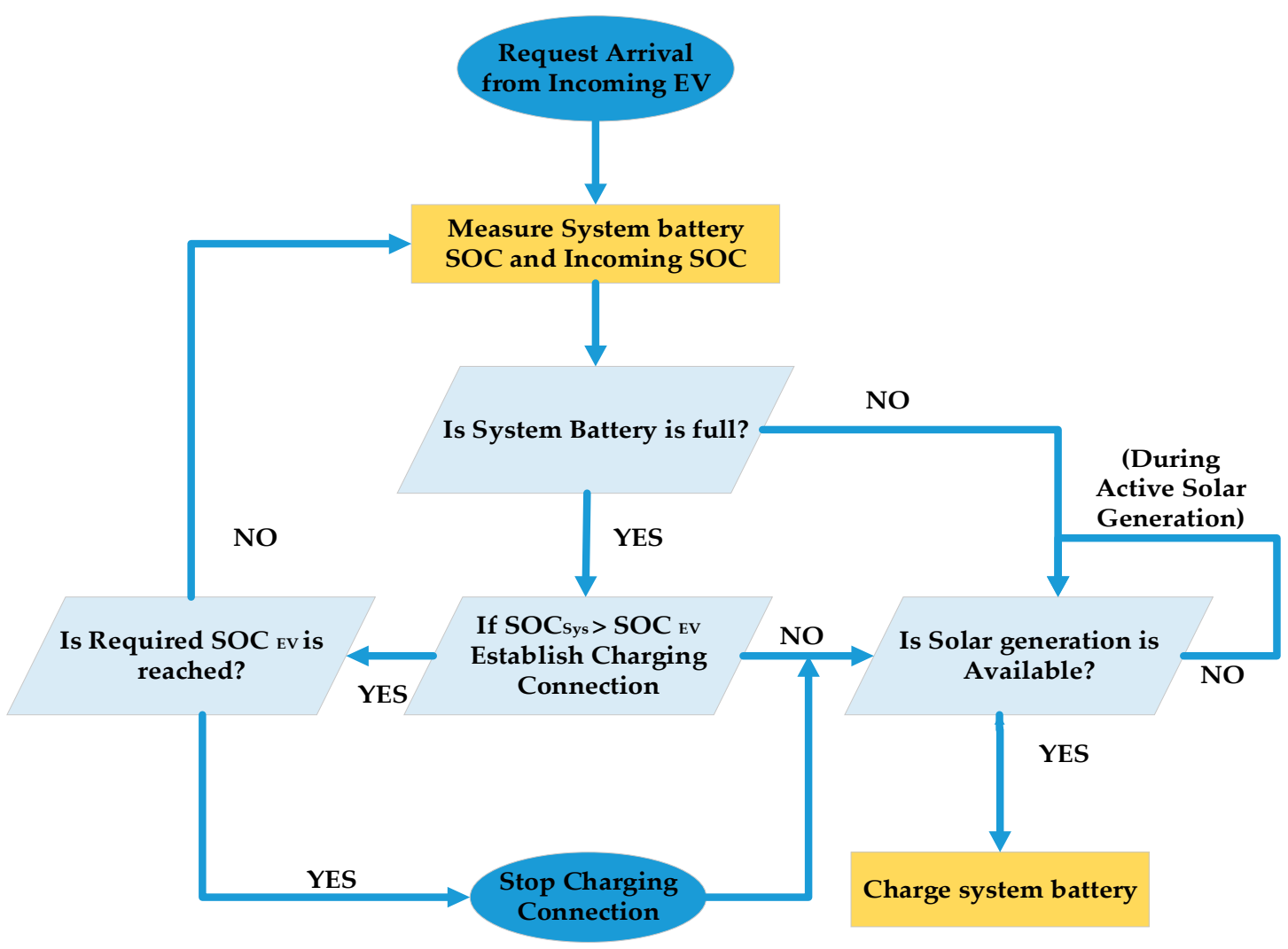

Figure 11. Proposed algorithm for SPRCS.

Based on the above algorithm, the system batteries got charged when there was abundant solar generation. The system would measure its SOC whenever there was charging or discharging sessions. Incoming request from EVs to get charged was monitored by the controller. The controller would compare the SOCs of both EV and the system, and then the system would initiate a charging session. Once the charging session was initiated, the controller would keep measuring the updated SOCs, and as per the algorithm, the controller may engage or disengage the charging session. The above constraints were simulated in MATLAB, and the proposed SPRCS could utilized for emergency charging.

\section{Results and Discussion}

The proposed system consists of a solar panel block where irradiance and the daily average temperature was given as input. The power generated from the SPV was then connected to the maximum power point technique MPPT controller maintaining constant DC voltage. As per the schematic, the system batteries were connected directly to the MPPT controller. In this design, the perturb and observe method was used for MPPT. The essential operation of maximum power was monitored continuously and fed as feedback to the controller. By either increasing or decreasing the operating voltage, it was possible to maintain maximum power in the system. The maximum power output from the MPPT was directly connected to the boost converter to boost up the voltage to the desired level. From the DC link, the batteries were connected. Based on the provided algorithm, the charging and discharging of batteries took place. 
In this paper, SPRCS was intended for emergency charging. Therefore, the algorithm dealt with collecting SOC from the incoming EV. Then based on the available SOC in system batteries and the provided technical constraints, the controller would allow the power flow between system batteries and EV battery. In order to provide rapid charging, the algorithm was programmed in such a way that SPRCS would charge the EV required level of the available SOC requested by the user. With an additional amount of charging, the EVs would able to reach a nearby charging station or workplace charging or home charging.

The first part of the simulation showed and explained about the standalone solar charging system to charge the proposed system. The proposed system consisted of batteries with the capacity of $279 \mathrm{Ah}$ and $403 \mathrm{~V}$. The solar system is fed with real-time irradiance and temperature data for the chosen location Subang Jaya, Malaysia. The array power was maintained at maximum by using an MPPT controller. From the controller, it was fed to boost converter to charge the system batteries (on-board batteries). The second part of the simulation showed the discharging of the on-board batteries to charge incoming EVs. The plug and play SPRCS was simulated using MATLAB/Simulink software shown in Figure 12a,b. The system consisted of standalone $20 \mathrm{kWp} \mathrm{SPV} \mathrm{that} \mathrm{was} \mathrm{connected} \mathrm{to} \mathrm{the} \mathrm{MPPT}$ controller. The MPPT controller was driven by the perturb and observation method. Incoming EVs battery was simulated as an incoming battery, which was directly coupled to the system batteries as direct coupling lead to fewer losses when compared with another available system. However, the main drawback of the system was that once the considered amount of charge was fed to EV battery the system battery would tend to lose its charge, which in turn will reduce the voltage. Therefore as of now, the present system after particular charging sessions, the system batteries cannot function in fast charging mode. The real-time input for the chosen location as a signal to the solar panel module in Simulink is shown in Figure 13.

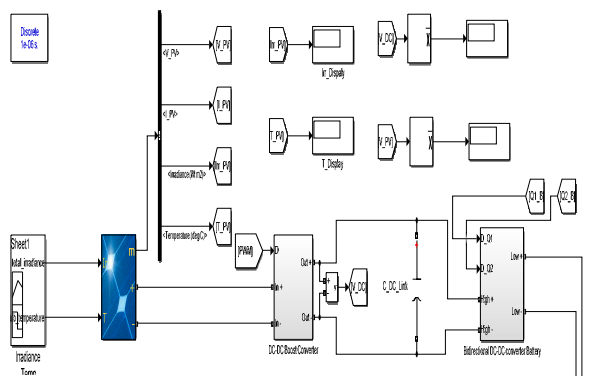

(a)

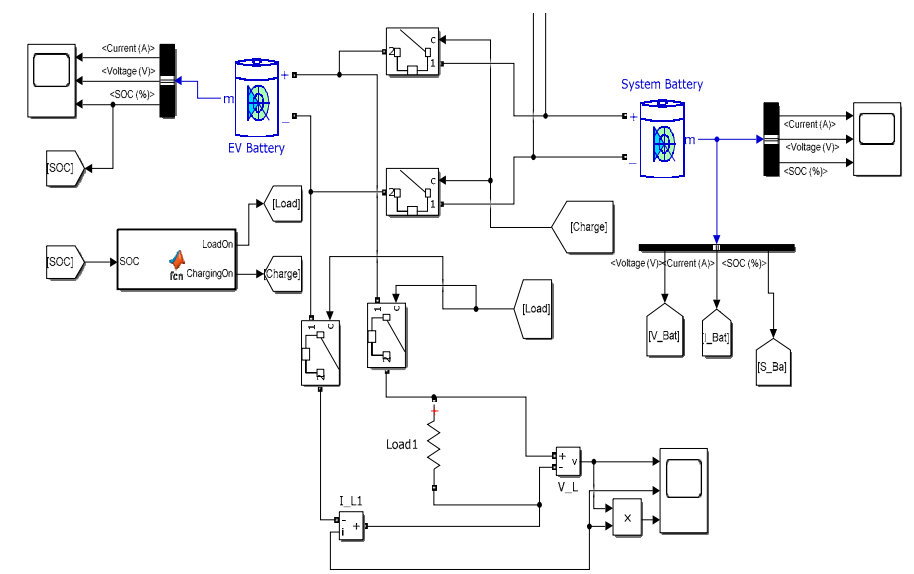

(b)

Figure 12. (a) Simulation model of plug and play SPRCS (PV system alone); (b) simulation model of plug and play SPRCS (battery section). 

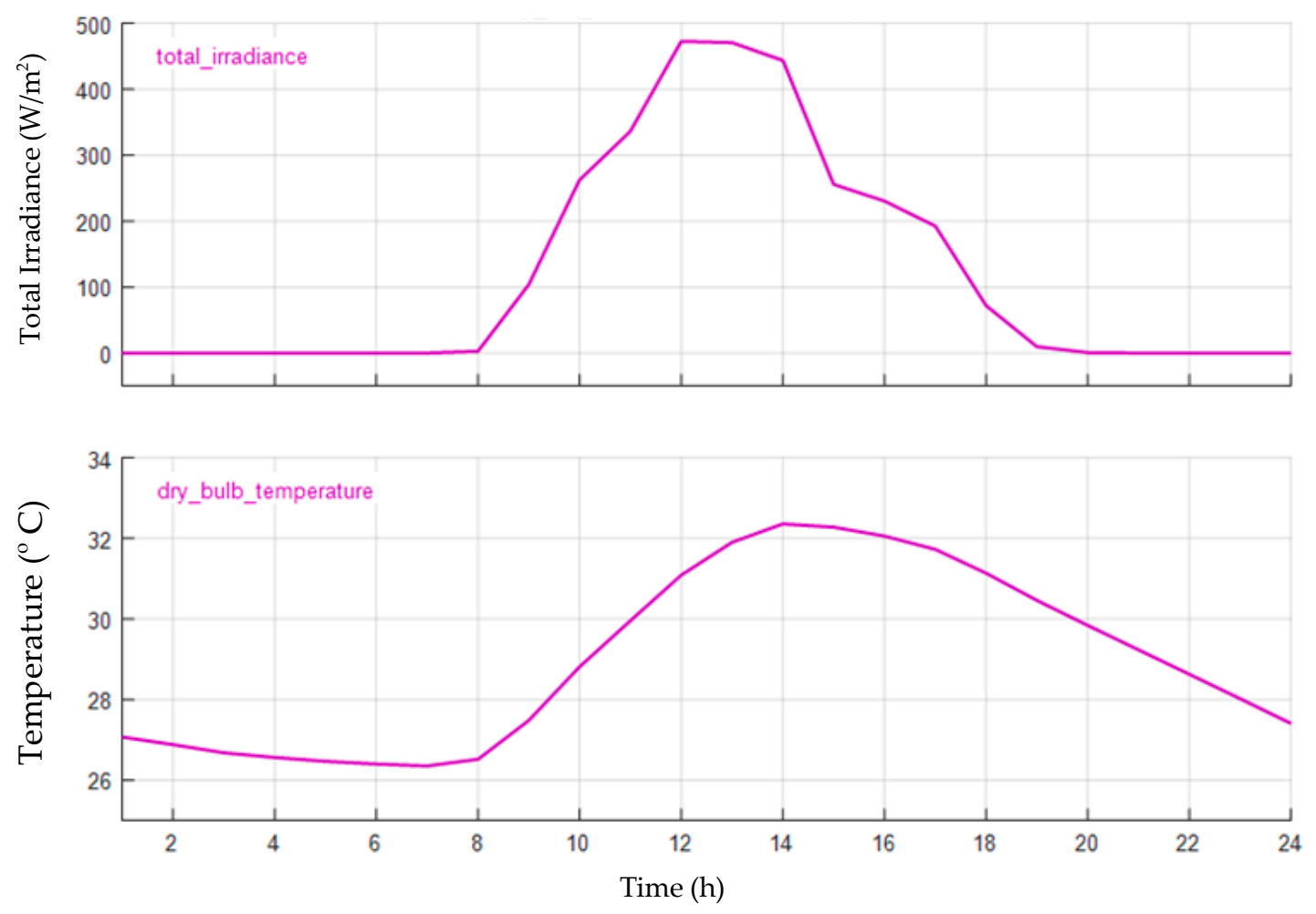

Figure 13. Input data to the solar panel.

The voltage, current, and power produced from the SPV in which from the curve, it was understood that system batteries were charged during the entire generation are shown in Figure 14a-c.

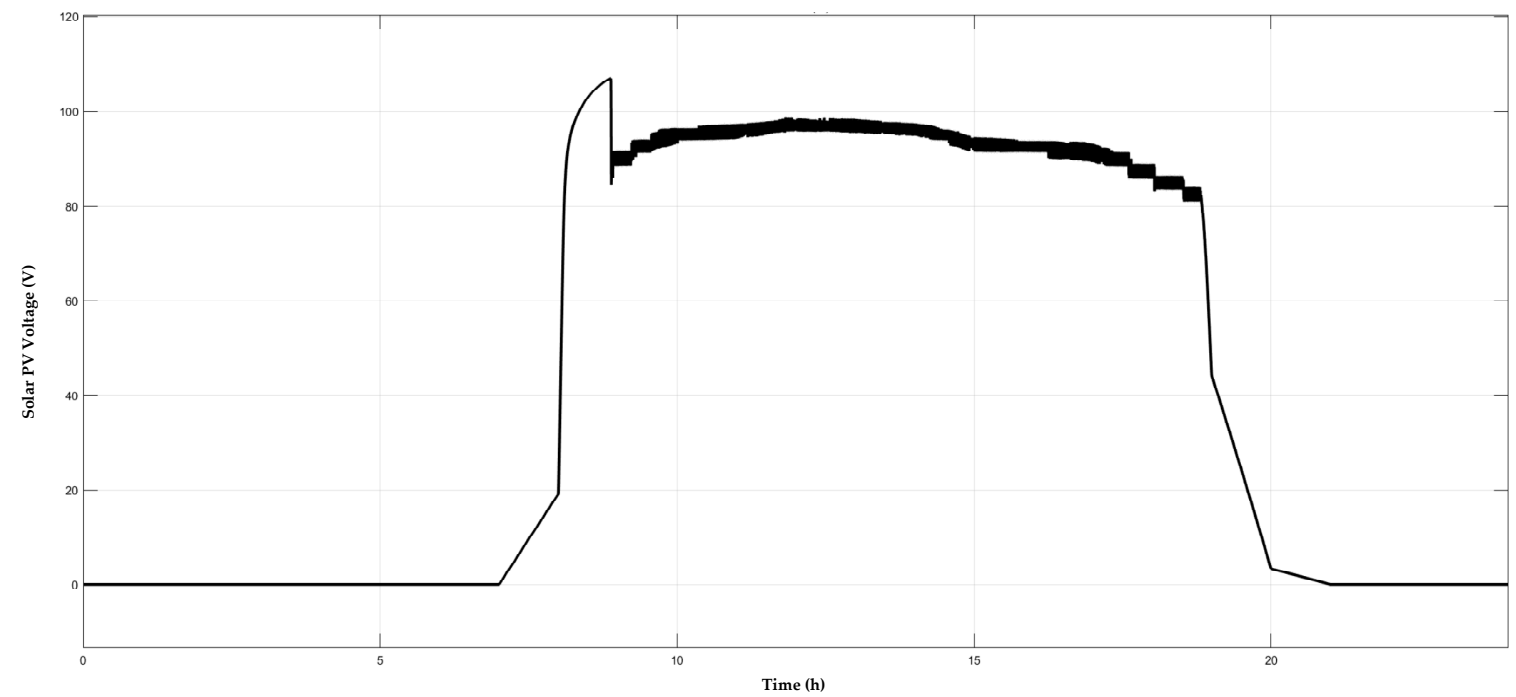

(a)

Figure 14. Cont. 


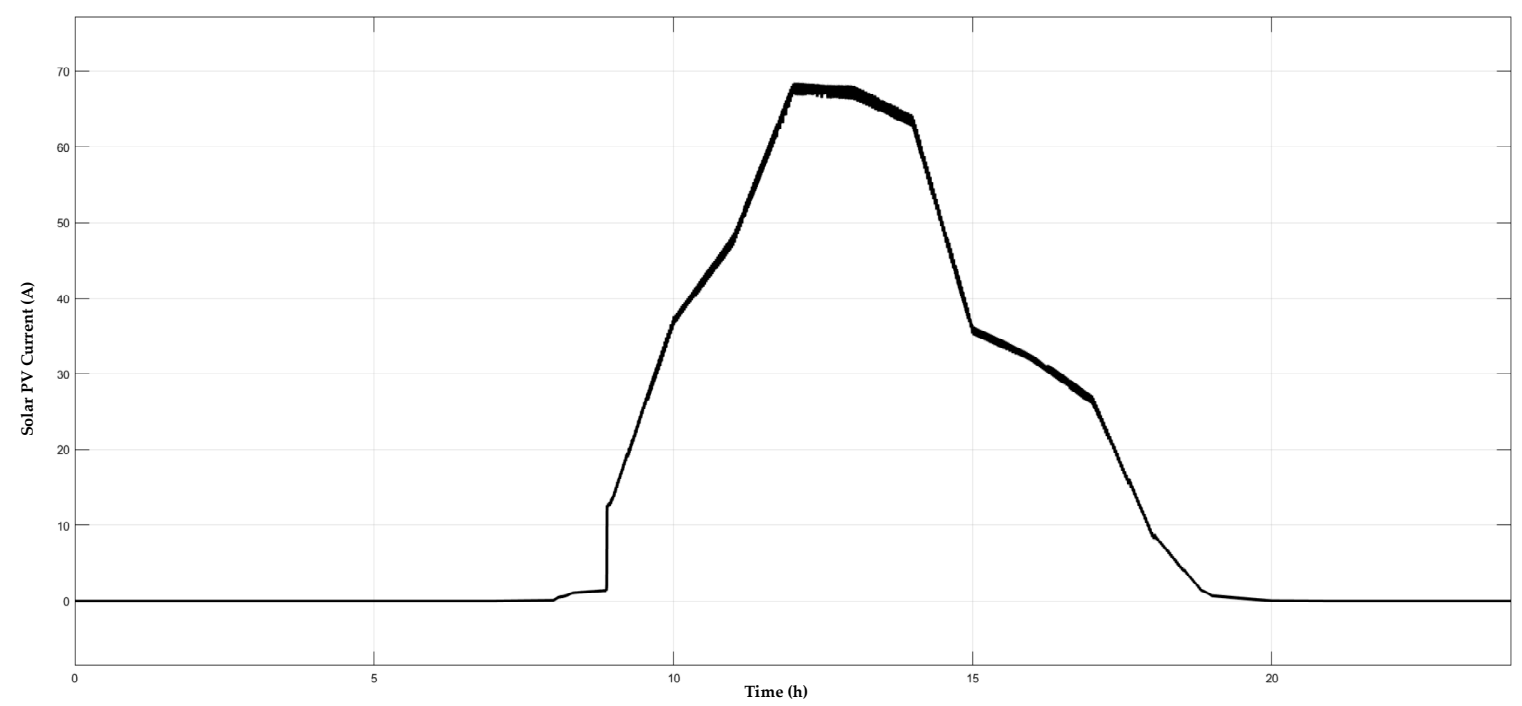

(b)

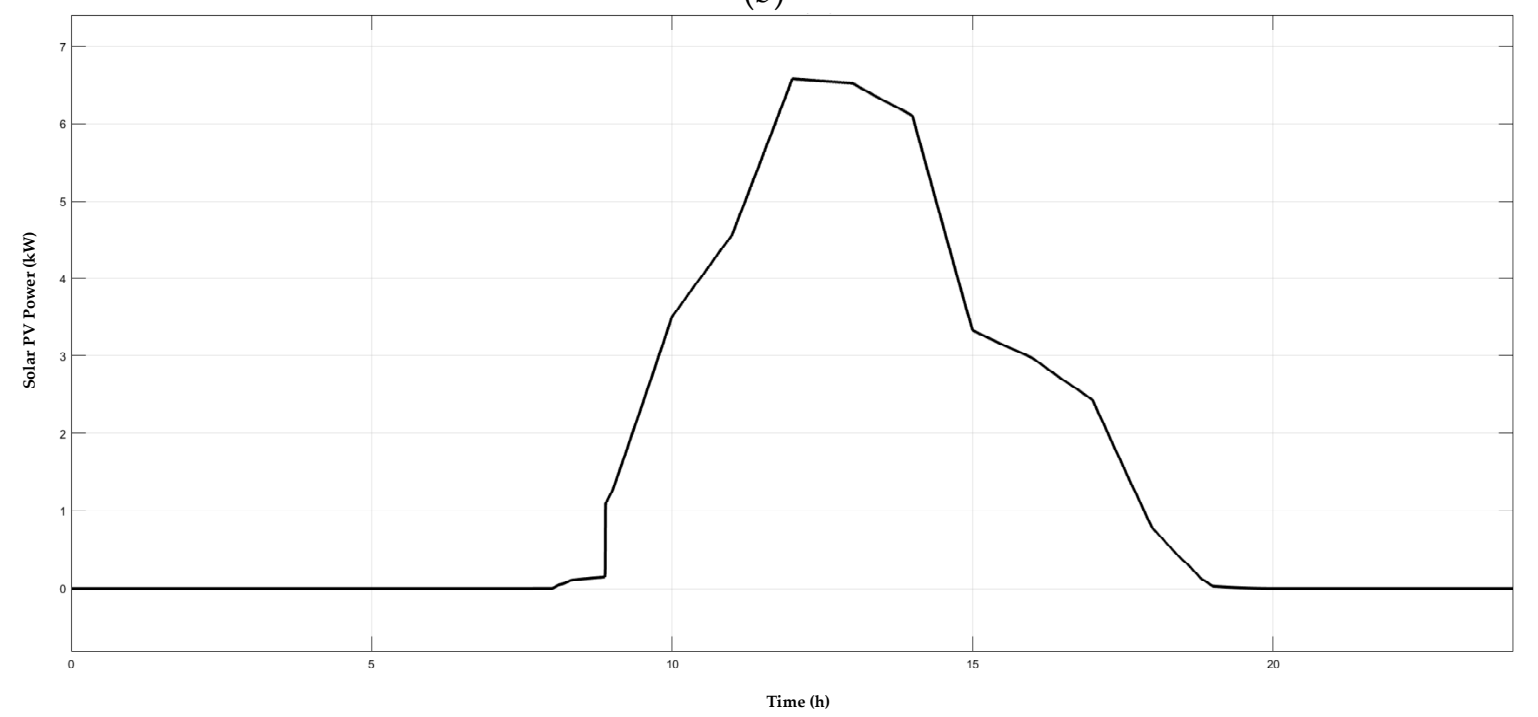

(c)

Figure 14. (a) Voltage characteristic curve for PV system; (b) current characteristic curve for PV system; (c) power characteristic curve for PV system.

The battery discharging to feed the load, such as EV battery, is shown in Figures 15-17. From the analysis of the SPRCS, Nissan LEAF ASCENTA [41] $40 \mathrm{kWh}$ can give up to 168 miles. Which in turn states that rapid charging gives Nissan LEAF ASCENTA a 100-mile charge in $10.25 \mathrm{~min}$. The above system output is provided without considering losses. Based on the design and from the charging curves, it is evident that charging from $20 \%$ to $80 \%$ would take approximately $10.25 \mathrm{~min}$. Once we implement a real-time system there might be $5 \%$ to $10 \%$ more time to charge by considering the real-time system losses, battery temperature, and DOD of system battery the designed SPRCS could equally provide rapid charging as stated by CHArge de Move (CHAdeMO) [42]. 

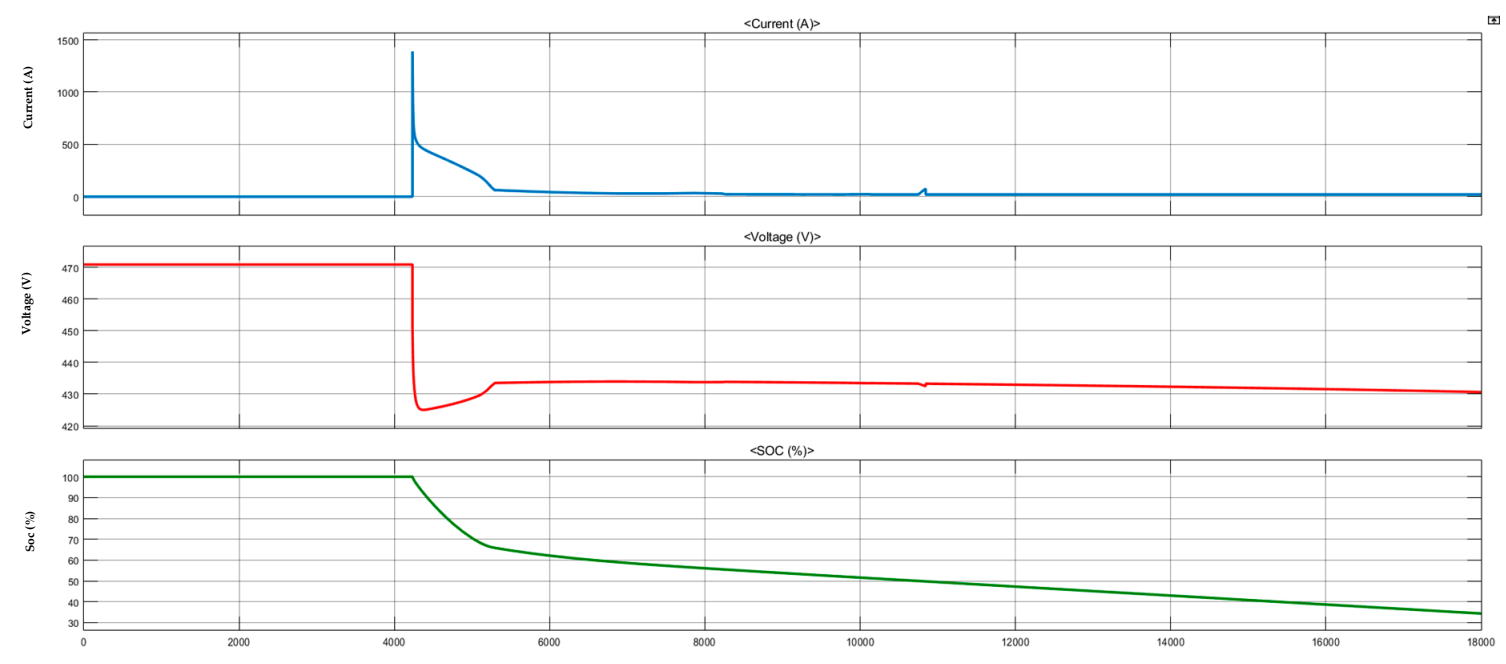

Time (S)

Figure 15. Characteristic curves for system battery.

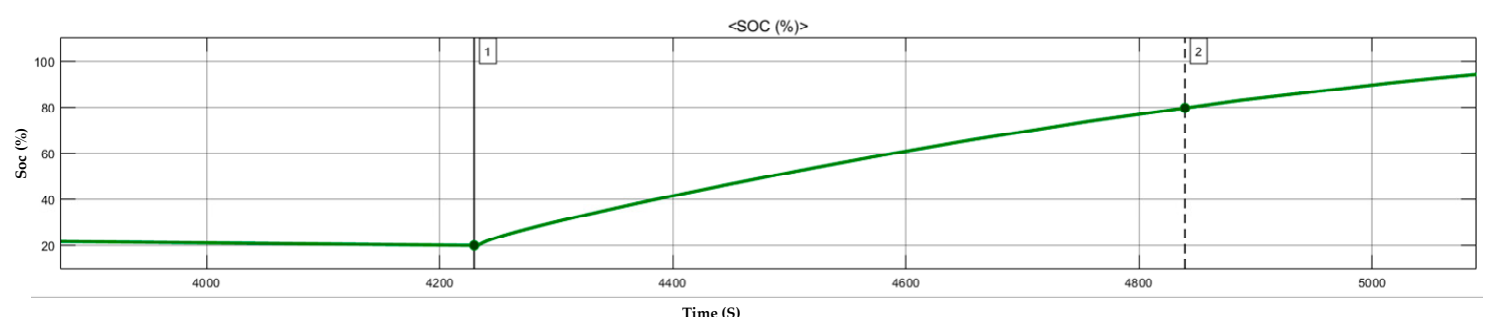

Figure 16. SOC from $20 \%$ to $80 \%$.
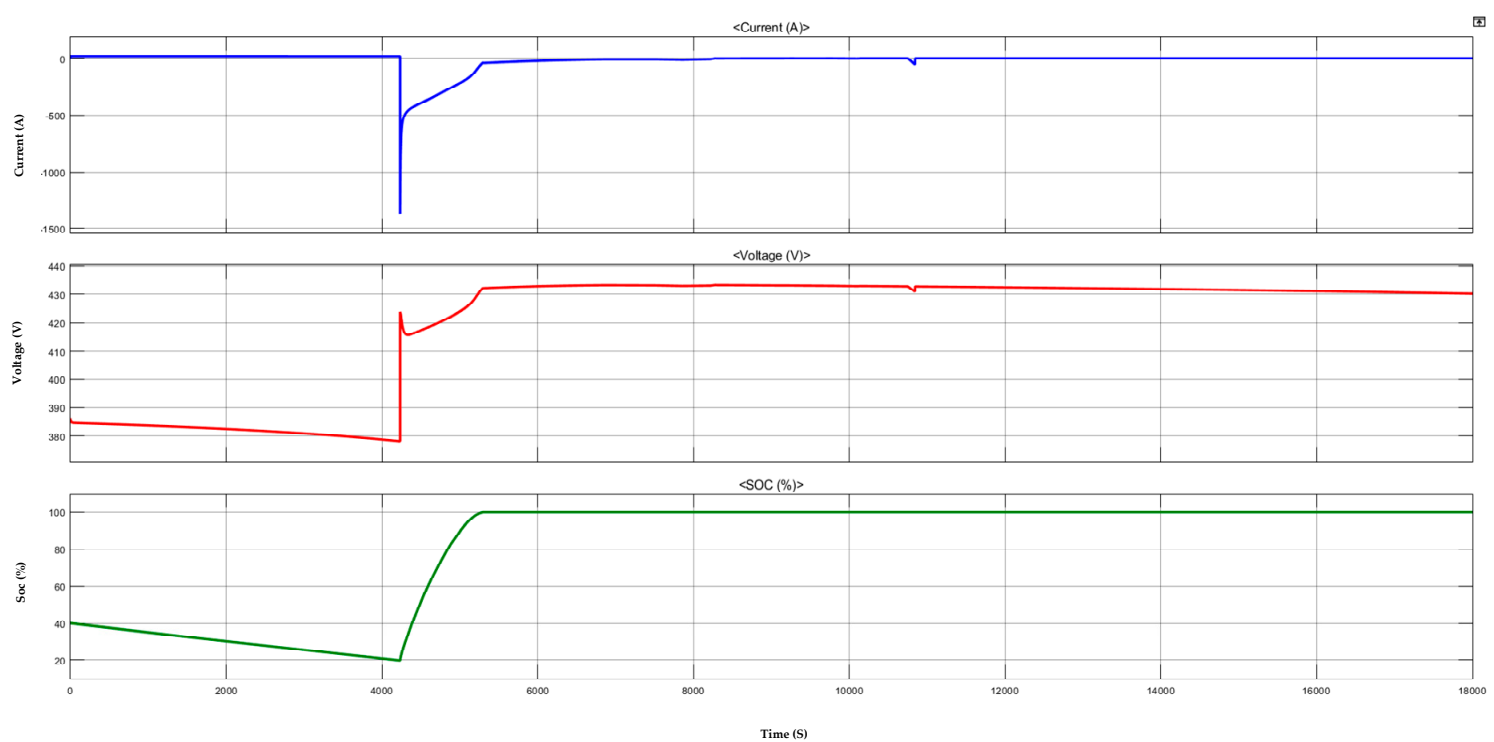

Figure 17. Characteristic curves for incoming electric vehicle (EV) battery.

\section{Economics and Carbon Balance}

The proposed SPRCS consisted of a modular 3D structure for bifacial solar modules, system batteries, charge controllers, and three-phase inverters along with cooling unit that could be equipped in the 20-foot container trailer. On a rough investment to design and construct SPRCS that could consist of the following components and its approximate prices in MYR is given in Table 5. As this was proposed as a concept of future SPRCS, the rates incurred for the support, settings, wiring, and other miscellaneous were not considered. 
Table 5. System costs.

\begin{tabular}{ccc}
\hline Equipment & Units & Cost in MYR \\
\hline PV modules & 52 of 360 Wp & 18,950 \\
Supports/Integration (Structure and trailer) & As required and one trailer & 6000 \\
Batteries & 8 of $50 \mathrm{~V} / 260 \mathrm{Ah}$ & 214,900 \\
Charge Controller & 1 & 5000 \\
Gross investment (excluding Taxes) & - & 244,850 \\
Assuming 6\% tax & - & 14,931 \\
Gross investment & - & 263,781 \\
Annuities (loan 5\% over 25 years) & Per year & 18,716 \\
Battery replacement & 5 years of lifetime & 3000 \\
Total yearly cost & Per year & 21,716 \\
Used energy cost & Per kWh & 1.04 \\
\hline
\end{tabular}

By considering government taxes, annuities and running costs, we can be in the position to say the cost of the energy produced would be 1.04 Myr. Based on the SPRCS produced emissions would be $36.54 \mathrm{tCO}_{2}$. The produced emission was a summation of emissions produced by modules of $34,254 \mathrm{Kg}$ $\mathrm{CO}_{2}$ and support structure including batteries, and container trailer was $2289 \mathrm{Kg} \mathrm{CO}_{2}$. It can be noted that the emissions from solar modules have a significant contribution of around $93.7 \%$ of the total emissions. From the SPV the replaced emissions were $397.1 \mathrm{t} \mathrm{CO}_{2}$. On an average system lifetime of 25 years and considering annual degradation of $1 \%$ the $\mathrm{CO}_{2}$ emission balance could be of $316.4 \mathrm{t} \mathrm{CO}_{2}$. As per the reference [43], the avoided Emissions calculator, $232.4 \mathrm{GWh}$ of solar photovoltaic energy avoided 0.1541 million tonnes of $\mathrm{CO}_{2}$ in 2016 with the energy mix of $42.2 \%$ coal, $53.6 \%$ natural gas and $4.2 \%$ of oil. Therefore, an EV charging station powered by solar photovoltaic energy would be more advantageous than any other energy mix.

\section{Summary}

From the above analysis, it was shown that the mobile plug and play SPRCS was designed with a $20 \mathrm{kWp}$ standalone solar power plant with a system battery capacity of 279 Ah along with direct control to transfer the power from system batteries to the incoming EVs. The 3D modular structure was utilized for erecting panels on the container trailer in a futuristic approach. However, in order to get a maximum yield on the collector plane for the location of Subang Jaya, Malaysia, the fixed tilt angle was considered as $3^{\circ}$. The entire system was designed using PVsyst software and analysis was carried out in MATLAB/Simulink. Standalone SPRCS is designed and analysed in MATLAB/SIMULINK to calculate the time taking to charge the incoming EV battery from the system battery. It was found that time taken to charge the EV battery from $20 \%$ to $80 \%$ was $10.25 \mathrm{~min}$.

\section{Conclusions}

It is evident that due to the rise in EVs in future, the rise in demand for rapid charging station will increase. Due to this situation, there will be tremendous stress on the distribution grid. All EV owners would like to charge their vehicle like fuel in a gas station. So various research works are working on to increase the life cycle of batteries, increasing the power density of batteries, and designing of more intense rapid stations. However, during emergencies as well as the gathering where there is limited EV parking or no parking slots for charging, the proposed SPRCS can be a viable solution.

With further designing of intelligent controllers and utilization of high-efficiency solar modules, there are many possibilities to reduce the size of the system as well as the cost incurred to construct the system. The above-proposed system can also act as an ancillary service provider in which it will be further analysed in upcoming research work. The above system is limited to the availability of charge in the system batteries, so when the battery voltage level decreases, the SPRCS may act as a level two charging facility. 
Author Contributions: Conceptualization, C.A.V., R.A. and K.S.P.O.; writing the manuscript, K.S.P.O. and G.R.; review and editing of the manuscript, C.A.V. and R.A.

Funding: This research was funded by Taylor's University through its TAYLOR'S PhD SCHOLARSHIP Programme through grant TUFR/2017/001/01. Meanwhile the APC was funded by UNITEN BOLD publication fund.

Acknowledgments: This work was supported by Taylor's University through its TAYLOR'S PhD SCHOLARSHIP Programme through grant TUFR/2017/001/01.

Conflicts of Interest: The authors declare no conflict of interest.

\section{References}

1. International Renewable Energy Agency. Electric Vehicles-Technology Brief; International Renewable Energy Agency: Abu Dhabi, UAE, 2017; ISBN 9789295111004.

2. EV Charging Made Easy. Available online: https://chargev.my/ (accessed on 2 July 2019).

3. International Energy Agency. Global EV Outlook 2018; International Energy Agency: Paris, France, 2018.

4. IEA. Global EV Outlook 2019 to Electric Mobility; IEA: Paris, France, 2019.

5. Gartner, J. Mobile EV Chargers Deliver Power Where It's Needed. Available online: https://chargedevs.com/ features/mobile-ev-chargers-deliver-power-where-its-needed/ (accessed on 5 August 2019).

6. EV Safe Charge. EV Charge Mobile for All Your Event Charging Needs. Available online: https://evsafecharge. com/mobile-ev-charging-stations/ (accessed on 5 August 2019).

7. Hawkins, A.J. Volkswagen's Mobile Charging Station Will Help Solve a Key Problem with EVs. Available online: https:/www.theverge.com/2019/1/2/18165265/volkswagen-ev-mobile-charging-stationbattery (accessed on 5 August 2019).

8. Dai, Q.; Liu, J.; Wei, Q. Optimal photovoltaic/battery energy storage/electric vehicle charging station design based onmulti-agent particle swarm optimization algorithm. Sustainability 2019, 11, 1973. [CrossRef]

9. Kadar, P.; Varga, A. PhotoVoltaic EV charge station. In Proceedings of the IEEE 11th International Symposium on Applied Machine Intelligence and Informatics (SAMI 2013), Herl'any, Slovakia, 31 January-2 February 2013; pp. 57-60.

10. Chen, Q.; Liu, N.; Wang, C.; Zhang, J. Optimal power utilizing strategy for PV-based EV charging stations considering Real-time price. In Proceedings of the 2014 IEEE Conference and Expo Transportation Electrification Asia-Pacific (ITEC Asia-Pacific), Beijing, China, 31 August-3 September 2014; pp. 1-6.

11. Liu, J.; Tang, H.; Ping, Z.; Zhou, L. Optimal charging control for electric vehicles in stand-alone PV charging stations. In Proceedings of the 11th World Congress on Intelligent Control and Automation, Shenyang, China, 29 June-4 July 2014; pp. 1749-1754.

12. Islam, M.S.; Mithulananthan, N.; Bhumkittipich, K. Feasibility of PV and battery energy storage based EV charging in different charging stations. In Proceedings of the 2016 13th International Conference on Electrical Engineering/Electronics, Computer, Telecommunications and Information Technology (ECTI-CON), Chiang Mai, Thailand, 28 June-1 July 2016; pp. 1-6.

13. Demeter, L.N.; Turcin, V.; Hanek, M.; Vataselu, G.; Zorlescu, B. Modular solution for charging the batteries of electric bikes parked on public domain. In Proceedings of the 2017 Electric Vehicles International Conference (EV), Bucharest, Romania, 5-6 October 2017; pp. 1-5.

14. Mouli, G.R.C.; Kefayati, M.; Baldick, R.; Bauer, P. Integrated PV charging of EV fleet based on energy prices, V2G, and offer of reserves. IEEE Trans. Smart Grid 2019, 10, 1313-1325. [CrossRef]

15. Zhang, Y.; He, Y.; Wang, X.; Wang, Y.; Fang, C.; Xue, H.; Fang, C. Modeling of fast charging station equipped with energy storage. Glob. Energy Interconnect. 2018, 1, 145-152.

16. Aluisio, B.; Dicorato, M.; Ferrini, I.; Forte, G.; Sbrizzai, R.; Trovato, M. Optimal Sizing Procedure for Electric Vehicle Supply Infrastructure Based on DC Microgrid with Station Commitment. Energies 2019, $12,1901$. [CrossRef]

17. Yousif, F.; Alghoul, M.A.; Alfegi, E.; Asim, N. Simulation of Hybrid PV-“3 Phase Grid” Electric Vehicle Charging System. In Latest Trends in Renewable Energy and Environmental Informatics; kuala lumpur, Malaysia; WSEAS Press: Cambridge, UK, 2013; pp. 304-309.

18. Fathabadi, H. Utilizing solar and wind energy in plug-in hybrid electric vehicles. Energy Convers. Manag. 2018, 156, 317-328. [CrossRef] 
19. Eldeeb, H.H.; Faddel, S.; Mohammed, O.A. Multi-Objective Optimization Technique for the Operation of Grid tied PV Powered EV Charging Station. Electr. Power Syst. Res. 2018, 164, 201-211. [CrossRef]

20. Esfandyari, A.; Norton, B.; Conlon, M.; McCormack, S.J. Performance of a campus photovoltaic electric vehicle charging station in a temperate climate. Sol. Energy 2019, 177, 762-771. [CrossRef]

21. Islam, M.S.; Mithulananthan, N. PV based EV charging at universities using supplied historical PV output ramp. Renew. Energy 2018, 118, 306-327. [CrossRef]

22. Bhatti, A.R.; Salam, Z. A rule-based energy management scheme for uninterrupted electric vehicles charging at constant price using photovoltaic-grid system. Renew. Energy 2018, 125, 384-400. [CrossRef]

23. Novoa, L.; Brouwer, J. Dynamics of an integrated solar photovoltaic and battery storage nanogrid for electric vehicle charging. J. Power Sources 2018, 399, 166-178. [CrossRef]

24. Grande, L.S.A.; Yahyaoui, I.; Gómez, S.A. Energetic, economic and environmental viability of off-grid PV-BESS for charging electric vehicles: Case study of Spain. Sustain. Cities Soc. 2018, 37, 519-529. [CrossRef]

25. Karmaker, A.K.; Ahmed, M.R.; Hossain, M.A.; Sikder, M.M. Feasibility assessment \& design of hybrid renewable energy based electric vehicle charging station in Bangladesh. Sustain. Cities Soc. 2018, 39, $189-202$.

26. Calise, F.; Cappiello, F.L.; Cartenì, A.; D'accadia, M.D.; Vicidomini, M. A novel paradigm for a sustainable mobility based on electric vehicles, photovoltaic panels and electric energy storage systems: Case studies for Naples and Salerno (Italy). Renew. Sustain. Energy Rev. 2019, 111, 97-114. [CrossRef]

27. Badea, G.; Felseghi, R.A.; Varlam, M.; Filote, C.; Culcer, M.; Iliescu, M.; Raboaca, M.S. Design and simulation of romanian solar energy charging station for electric vehicles. Energies 2019, 12, 74. [CrossRef]

28. Klingler, A.L. The effect of electric vehicles and heat pumps on the market potential of PV + battery systems. Energy 2018, 161, 1064-1073. [CrossRef]

29. Marczinkowski, H.M.; Østergaard, P.A. Residential versus communal combination of photovoltaic and battery in smart energy systems. Energy 2018, 152, 466-475. [CrossRef]

30. Savio, D.A.; Juliet, V.A.; Chokkalingam, B.; Padmanaban, S.; Holm-Nielsen, J.B.; Blaabjerg, F. Photovoltaic Integrated Hybrid Microgrid Structured Electric Vehicle Charging Station and Its Energy Management Approach. Energies 2019, 12, 168. [CrossRef]

31. Miceli, R.; Viola, F. Designing a sustainable university recharge area for electric vehicles: Technical and economic analysis. Energies 2017, 10, 1604. [CrossRef]

32. Ul-Haq, A.; Cecati, C.; Al-Ammar, E.A. Modeling of a photovoltaic-powered electric vehicle charging station with vehicle-to-grid implementation. Energies 2017, 10, 4. [CrossRef]

33. Bellocchi, S.; Manno, M.; Noussan, M.; Vellini, M. Impact of Grid-Scale Electricity Storage and Electric Vehicles on Renewable Energy Penetration: A Case Study for Italy. Energies 2019, 12, 1303. [CrossRef]

34. Domínguez-Navarro, J.A.; Dufo-López, R.; Yusta-Loyo, J.M.; Artal-Sevil, J.S.; Bernal-Agustín, J.L. Design of an electric vehicle fast-charging station with integration of renewable energy and storage systems. Int. J. Electr. Power Energy Syst. 2019, 105, 46-58. [CrossRef]

35. Ma, W.; Wang, W.; Wu, X.; Hu, R.; Tang, F.; Zhang, W. Control strategy of a hybrid energy storage system to smooth photovoltaic power fluctuations considering photovoltaic output power curtailment. Sustainability 2019, 11, 1324. [CrossRef]

36. Pasetti, M.; Rinaldi, S.; Flammini, A.; Longo, M.; Foiadelli, F. Assessment of Electric Vehicle Charging Costs in Presence of Distributed Photovoltaic Generation and Variable Electricity Tariffs. Energies 2019, 12, 499. [CrossRef]

37. Sun, Y.; Zhai, S.; Cui, H.; Nan, D.; Wang, K. Frequency regulation strategy for private EVs participating in integrated power system of REs considering adaptive Markov transition probability. Electr. Power Syst. Res. 2019, 173, 291-301. [CrossRef]

38. Han, X.; Liang, Y.; Ai, Y.; Li, J. Economic evaluation of a PV combined energy storage charging station based on cost estimation of second-use batteries. Energy 2018, 165, 326-339. [CrossRef]

39. Bernardi, M.; Ferralis, N.; Wan, J.H.; Villalon, R.; Grossman, J.C. Solar energy generation in three dimensions. Energy Environ. Sci. 2012, 5, 6880-6884. [CrossRef]

40. ABB EV Charging Infrastructure. Electric Vehicle Charging Infrastructure Terra 51 Charge Station; ABB B. V.: Rijswijk, The Netherlands, 2011; pp. 1-2. 
41. NISSAN. Range \& Charging. Available online: https://www.nissan.co.uk/vehicles/new-vehicles/leaf/ charging-range.html (accessed on 8 July 2019).

42. CHAdeMO Protocol. Available online: https://www.chademo.com/ (accessed on 11 July 2019).

43. IRENA. Avoided Emissions Calculator. Available online: https://www.irena.org/climatechange/AvoidedEmissions-Calculator (accessed on 6 August 2019). 